\title{
A MOLECULAR LINE SURVEY OF THE HIGHLY EVOLVED CARBON STAR CIT 6
}

\author{
Yong Zhang ${ }^{1}$, Sun KwoK ${ }^{1}$, AND Dinh-V-Trung ${ }^{2,3}$ \\ ${ }^{1}$ Department of Physics, University of Hong Kong, Pokfulam Road, Hong Kong, China; zhangy96@hku.hk, sunkwok@hku.hk \\ ${ }^{2}$ Institute of Astronomy and Astrophysics, Academia Sinica, P.O. Box 23-141, Taipei 106, Taiwan; trung@asiaa.sinica.edu.tw \\ Received 2008 May 12; accepted 2008 September 3; published 2009 February 9
}

\begin{abstract}
We present a spectral-line survey of the C-rich envelope CIT 6 in the $2 \mathrm{~mm}$ and $1.3 \mathrm{~mm}$ bands carried out with the Arizona Radio Observatory $12 \mathrm{~m}$ telescope and the Heinrich Hertz Submillimeter Telescope. The observations cover the frequency ranges of $131-160 \mathrm{GHz}, 219-244 \mathrm{GHz}$, and $252-268 \mathrm{GHz}$ with a typical sensitivity limit of $T_{R}<10 \mathrm{mK}$. A total of 74 individual emission features are detected, of which 69 are identified to arise from 21 molecular species and isotopologues, with five faint lines remaining unidentified. Two new molecules $\left(\mathrm{C}_{4} \mathrm{H}\right.$ and $\left.\mathrm{CH}_{3} \mathrm{CN}\right)$ and seven new isotopologues $\left(\mathrm{C}^{17} \mathrm{O},{ }^{29} \mathrm{SiC}_{2},{ }^{29} \mathrm{SiO},{ }^{30} \mathrm{SiO},{ }^{13} \mathrm{CS}, \mathrm{C}^{33} \mathrm{~S}\right.$, and $\left.\mathrm{C}^{34} \mathrm{~S}\right)$ are detected in this object for the first time. The column densities, excitation temperatures, and fractional abundances of the detected molecules are determined using rotation-diagram analysis. Comparison of the spectra of CIT 6 to that of IRC+10216 suggests that the spectral properties of CIT 6 are generally consistent with those of IRC+10216. For most of the molecular species, the intensity ratios of the lines detected in the two objects are in good agreement with each other. Nevertheless, there is evidence suggesting enhanced emission from $\mathrm{CN}$ and $\mathrm{HC}_{3} \mathrm{~N}$ and depleted emission from $\mathrm{HCN}, \mathrm{SiS}$, and $\mathrm{C}_{4} \mathrm{H}$ in CIT 6. Based on their far-IR spectra, we find that CIT 6 probably has a lower dust-to-molecular ratio than IRC+10216. To investigate the chemical evolution of evolved stars, we compare the molecular abundances in the asymptotic giant branch envelopes CIT 6 and IRC+10216 and those in the bright proto-planetary nebula CRL 618. The implication on the circumstellar chemistry is discussed.
\end{abstract}

Key words: circumstellar matter - ISM: molecules - line: identification - stars: AGB and post-AGB - stars:

individual (CIT 6) - surveys - radio lines: stars

\section{INTRODUCTION}

The late stages of stellar evolution from the asymptotic giant branch (AGB) to planetary nebulae (PNs) are now recognized as an active period of chemical synthesis of molecules. The detection and analysis of millimeter wave molecular emission lines are fundamental to the understanding of the physical conditions and chemical processes leading to chemical synthesis. Due to the rapid evolution of the star, the changing physical conditions, including dust, stellar winds, shock waves, UV emission, and X-rays from the central star, play different roles in circumstellar chemistry. This leads to different circumstellar chemical compositions corresponding to different evolutionary stages. The envelopes around C-rich stars, with their enhanced carbon abundance, provide a perfect cradle for molecule formation. Hitherto, more than 60 molecular species have been detected in C-star envelopes (Glassgold 1996; Olofsson 1997; Cernicharo et al. 2000; Ziurys et al. 2007), most of which were discovered through their rotational lines at millimeter wavelengths.

Recent improvement in telescope design and receiver performance enables us to detect new molecular emission with a higher sensitivity, and thus gives the possibility of shedding new light on circumstellar chemistry. The most frequently investigated C-star envelope is IRC+10216, which is one of the richest molecular sources in the sky. Several molecular line surveys have been presented for this object (see Cernicharo et al. 2000; He et al. 2008, and the references therein), which was found to harbor extremely abundant carbon chain and metalcontaining molecules. IRC+10216 has been frequently used as a standard reference for the chemical compositions of late-type stars. This inevitably invites the issue whether IRC+10216 is a

\footnotetext{
3 On leave from Institute of Physics and Electronics, Vietnamese Academy of Science and Technology, 10 DaoTan Street, BaDinh, Hanoi, Vietnam.
}

chemically unique late-type star. To settle this question, we require systematic surveys of molecular line emission from other C-star envelops. In the present study, we report a spectral-line survey of the C-star envelope CIT 6 at millimeter wavelengths. This allows us to compare the similarity and difference in the chemical compositions between the two C-star envelopes.

CIT 6 (RW LMi, GL 1403, IRC+30219, IRAS 10131+3049) was first discovered during the Caltech $2 \mu \mathrm{m}$ sky survey and was among the 14 very red IR-bright optical-faint sources found (Ulrich et al. 1966). CIT 6 is characterized by its very low color temperature, implying that the star is surrounded by a very thick dust envelope, and has been identified as a long-period variable with a period of about 628 days (Alksnis 1995). From the period-luminosity relation, Cohen \& Hitchon (1996) estimated the distance of CIT 6 to be $400 \pm 50 \mathrm{pc}$, which is slightly more than IRC+10216, which has a distance of between $\sim 120 \mathrm{pc}$ (Groenewegen et al. 1998) and 150 pc (Lucas \& Guélin 1999). CIT 6 is believed to be more evolved and has a lower massloss rate compared to IRC+10216 (see e.g., Fukasaku et al. 1994).

The large polarization found in the visible and IR wavelengths implies that the distribution of circumstellar material around the star is asymmetric (Kruszewski 1968; Dyck et al. 1971). Multiwavelength imaging observations have been performed to study the structure of the nebula around CIT 6. The optical images obtained by the Hubble Space Telescope (HST) and the near-IR images of CIT 6 obtained by the Keck-I telescope have revealed a bipolar dust envelope and an elongated component with time-variable asymmetry (Monnier et al. 2000). Several scattering arcs were revealed by the HST-Near-Infrared Camera and Multi-Object Spectrometer (NICMOS) imaging polarimetry (Schmidt et al. 2002). These arcs are nearly concentric and extend to large stellar radii. Mid-IR images of CIT 6 were obtained by Lagadec et al. (2005) using the ESO $3.6 \mathrm{~m}$ 
telescope. A cometary-like feature was revealed in their $9.7 \mu \mathrm{m}$ image.

There have been several observations of molecular lines in CIT 6 at millimeter wavelengths. Henkel et al. (1985) reported observations of a few molecular lines in CIT 6 and IRC+10216 between 18 and $150 \mathrm{GHz}$. They found that relative abundances of observed molecules in the two sources have no significant differences. Using the Nobeyama $45 \mathrm{~m}$ radio telescope, Fukasaku et al. (1994) observed a few transitions in the frequency ranges between $39-47 \mathrm{GHz}$ and $85-91 \mathrm{GHz}$ in a sample of evolved stars (including CIT 6) and found that the abundance of HNC increases with the evolutionary stage of the stars. Bujarrabal et al. (1994) presented observations of ten molecular transitions in $\mathrm{C}$-rich and O-rich circumstellar envelopes (including CIT 6) with the IRAM $30 \mathrm{~m}$ radio telescope at $1.3 \mathrm{~mm}, 2 \mathrm{~mm}$, and $3 \mathrm{~mm}$ windows. A recent molecular line survey was presented by Woods et al. (2003) using the SEST $15 \mathrm{~m}$ and Onsala $20 \mathrm{~m}$ telescopes. They found that CIT 6 stands out from the other $\mathrm{C}$-rich envelopes due to its high $\mathrm{CN} / \mathrm{HCN}$ ratio and low $\mathrm{HNC} / \mathrm{HCN}$ ratio. To date, the molecular species positively detected in CIT 6 at millimeter wavelengths include $\mathrm{CO},{ }^{13} \mathrm{CO}, \mathrm{CN},{ }^{13} \mathrm{CN}, \mathrm{CS}, \mathrm{SiO}, \mathrm{SiS},{ }^{29} \mathrm{Si}^{32} \mathrm{~S}, \mathrm{C}_{2} \mathrm{H}, \mathrm{SiC}_{2}$, $\mathrm{HCN}, \mathrm{H}^{13} \mathrm{CN}, \mathrm{HNC}, \mathrm{C}_{3} \mathrm{~N}, \mathrm{HC}_{3} \mathrm{~N}, \mathrm{HC}^{13} \mathrm{CCN}, \mathrm{HCC}^{13} \mathrm{CN}$, and $\mathrm{HC}_{5} \mathrm{~N}$.

In this paper, we present the first systematical line survey of CIT 6 at the $2 \mathrm{~mm}$ and $1.3 \mathrm{~mm}$ windows, using the Arizona Radio Observatory (ARO) $12 \mathrm{~m}$ telescope and the Heinrich Hertz Submillimeter Telescope (SMT). The observations are described in Section 2. In Section 3 we present the identifications and abundance calculations of the detected molecular species. In Section 4 we discuss the implication of our findings on circumstellar chemistry. The conclusions are given in Section 5.

\section{OBSERVATIONS AND DATA REDUCTION}

The observations were carried out in a beam-switching mode with an azimuth beam throw of $2^{\prime}$ during the period from 2005 April to 2006 September. Pointing was checked by observations of a planet every $2 \mathrm{hr}$. The $131-160 \mathrm{GHz}$ ( $2 \mathrm{~mm}$ window) spectra were obtained with the ARO $12 \mathrm{~m}$ telescope at Kitt Peak, and the 219-244 GHz and 252-268 GHz (1.3 mm window) spectra with the SMT $10 \mathrm{~m}$ telescopes on Mount Graham, Arizona. The 2 and $1.3 \mathrm{~mm}$ dual-channel SIS receivers were employed and operated in single sideband dual polarization mode with a typical image rejection ratio of more than $18 \mathrm{~dB}$. At the ARO $12 \mathrm{~m}$ telescope the spectrometer back ends were two 256-channel filter banks (FBs) with a channel width of $1 \mathrm{MHz}$ and a millimeter autocorrelator (MAC) with 3072 channels and $195 \mathrm{kHz}$ per channel. The spectrometers utilized at SMT were a 2048-channel acousto-optical spectrometer (AOS) with a channel width of $500 \mathrm{kHz}$ and 1024-channel Forbes Filter banks (FFBs) with a channel width of $1 \mathrm{MHz}$. The system noise temperatures were typically $150-400 \mathrm{~K}$ at $2 \mathrm{~mm}$ and $400-700 \mathrm{~K}$ at $1.3 \mathrm{~mm}$. The temperature scales at the ARO $12 \mathrm{~m}$ and the SMT, $T_{R}^{*}$ and $T_{A}^{*}$, respectively, were obtained using standard vane calibration. $A \sim 15 \%$ calibration error was obtained from a few strong lines detected in different spectrometers and different epochs. The main-beam brightness temperatures were derived through $T_{R}=T_{R}^{*} / \eta_{m}^{*}$ and $T_{R}=T_{A}^{*} / \eta_{m b}$, for the $12 \mathrm{~m}$ and the SMT data, respectively, where $\eta_{m}^{*}$ is the corrected beam efficiency $(\sim 0.75$; see the ARO $12 \mathrm{~m}$ manual for its definition) and $\eta_{m b}$ is the beam efficiency $(\sim 0.7)$. Both telescopes have a large beam size, covering the whole emission region.
The CLASS software package in GILDAS ${ }^{4}$ was used to reduce the spectra. After discarding the bad scans which were seriously affected by bandpass irregularities, we co-added the spectra from individual scans. The baseline was fitted with a low-order polynomial. In order to improve the signal-to-noise ratios, the spectra were smoothed and rebinned by a factor of 3 , yielding a typical rms noise temperature of less than $10 \mathrm{mK}$ in main beam brightness temperature units and a spectral resolution of $\sim 4 \mathrm{~km} \mathrm{~s}^{-1}$. Since each line has been observed by two different spectrometers, we can reduce the uncertainties caused by ripples and bad channels.

\section{RESULTS}

\subsection{Line Identification and Measurement}

A total of 74 individual features were detected in our survey, including some less-than-certain detections. Line identification is mainly based on the JPL catalog (Pickett et al. $1998)^{5}$ and the Cologne database for molecular spectroscopy (CDMS; Müller et al. 2001, 2005), ${ }^{6}$ which give the molecular line frequencies based on theoretical calculations. We also used the NIST Recommended Rest Frequencies for Observed Interstellar Molecular Microwave Transitions, ${ }^{7}$ which provides the molecular line frequencies derived from observations of various sources. Moreover, we utilized the recent observations of IRC+10216 and CRL 618 by He et al. (2008), Cernicharo et al. (2000), and Pardo et al. (2007) for reference. The complete spectra obtained with the ARO $12 \mathrm{~m}$ telescope and the SMT $10 \mathrm{~m}$ telescope are plotted in Figures 1 and 2 along with identified lines marked. Figures 3 and 4 give the detected molecular line profiles. Note that the two features at $221.459 \mathrm{GHz}$ and $241.458 \mathrm{GHz}$ clearly seen in Figure 2 are the strong $\mathrm{CO}$ lines from the image sideband. Among the detected features, 69 are identified to arise from 21 molecular species and their isotopic variants. Table 1 lists their assignments, peak and integrated intensities, and line widths species by species. The half-maximum line widths (FWHM) were obtained by fitting Gaussian line profiles. If a line has an unresolved hyperfine structure, the peak intensity of the strongest transition is given, and the integrated intensity and the FWHM are those of the combined feature.

Five faint features remain unidentified and they are listed in Table 2. Comparing with the unidentified line listing in the NIST frequency table, we find that the 148444, 255940, and $265936 \mathrm{MHz}$ lines have no previous recorded detections elsewhere, and the 257035 and $262255 \mathrm{MHz}$ may have corresponding $\mathrm{U}$ lines at 257015 and $262273 \mathrm{MHz}$ detected in Sgr B2 (N) (Nummelin et al. 1998).

A detailed description of the molecules detection is given below.

CO. The $J=2-1$ transitions of $\mathrm{CO},{ }^{13} \mathrm{CO}$, and $\mathrm{C}^{17} \mathrm{O}$ were detected at the $1.3 \mathrm{~mm}$ window. Figure 4 clearly shows that the shape of the $\mathrm{CO}$ line differs from that of the ${ }^{13} \mathrm{CO}$ line. The $\mathrm{CO}$ line shows a parabolic profile, while the ${ }^{13} \mathrm{CO}$ line has a double-peaked profile, suggesting the former is optically thick, while the latter is optically thin. Teyssier et al. (2006) observed the CO transitions from $J=1-0$ to $J=6-5$ in CIT 6. The shape of the $\mathrm{CO}(2-1)$ line obtained by our observations is very similar to their results (see their Figure 6). The CO (2-1)

\footnotetext{
4 GILDAS is developed and distributed by the Observatoire de Grenoble and IRAM.

5 http://spec.jpl.nasa.gov

6 http://www.ph1.uni-koeln.de/vorhersagen/

7 http://physics.nist.gov/cgi-bin/micro/table5/start.pl
} 

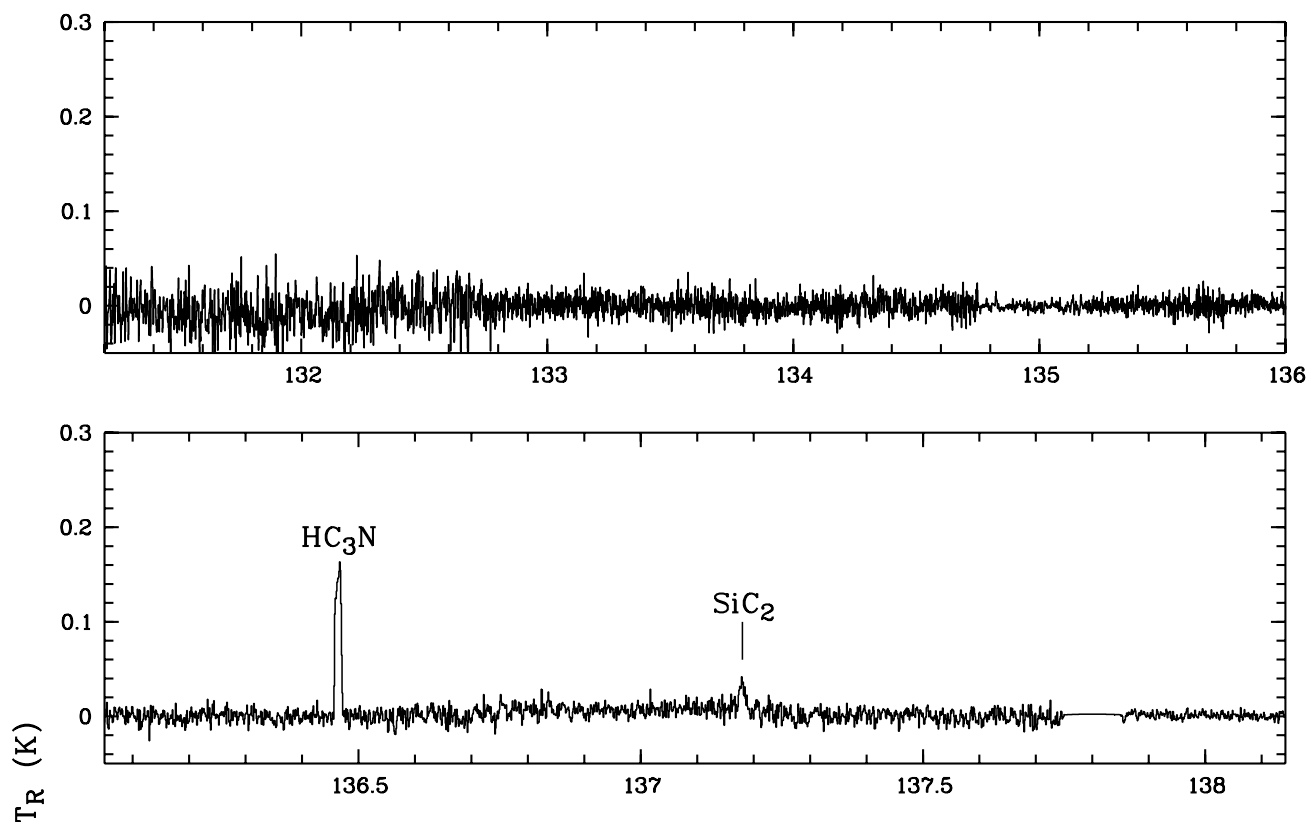

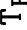
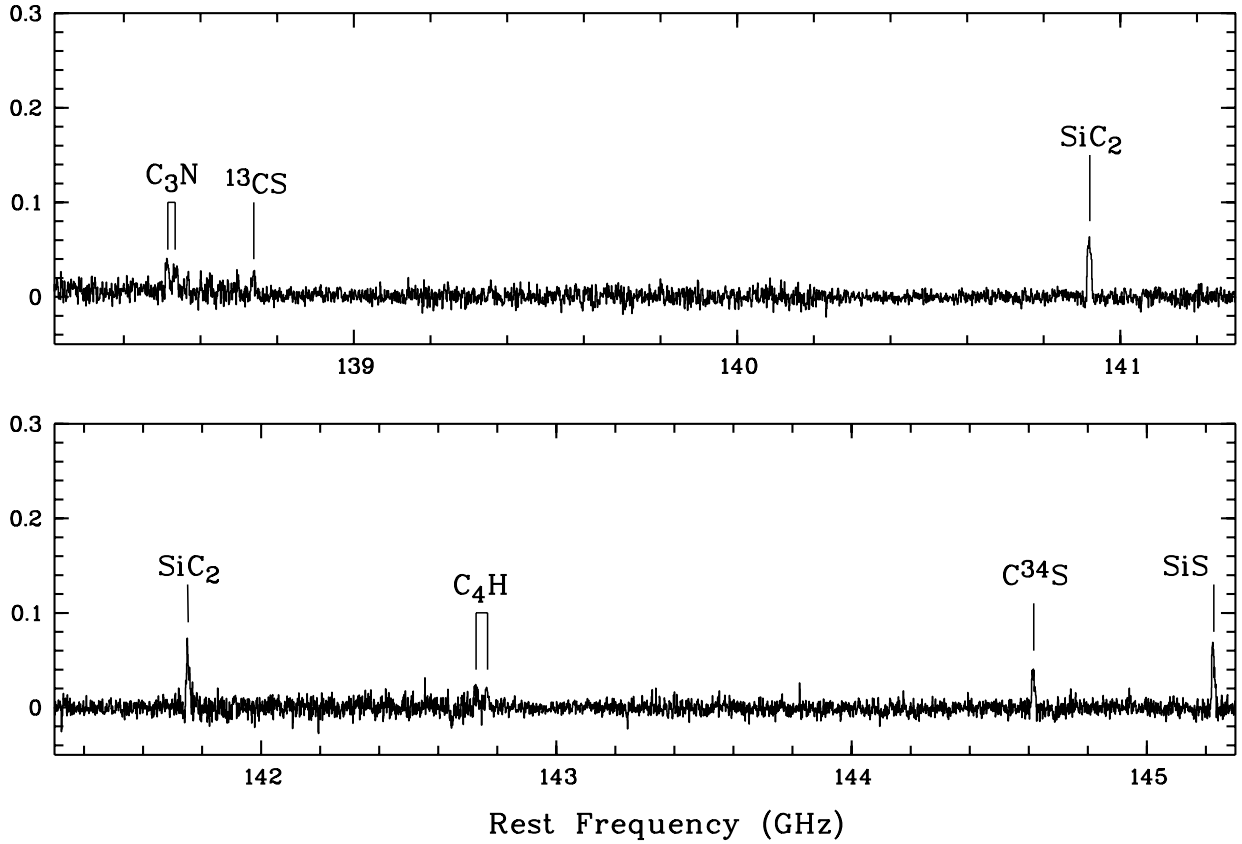

Figure 1. The spectrum of CIT 6 in the frequency range 131-160 GHz obtained with the ARO $12 \mathrm{~m}$ telescope. The spectra have been smoothed to a resolution of $1 \mathrm{MHz}$.

and ${ }^{13} \mathrm{CO}(2-1)$ lines have also been observed by Groenewegen et al. (1996) using the IRAM telescope in 1991. They obtained the integrated intensities of the $\mathrm{CO}(2-1)$ and ${ }^{13} \mathrm{CO}(2-1)$ lines to be 230 and $16.5 \mathrm{~K} \mathrm{~km} \mathrm{~s}^{-1}$, respectively, a factor of $\sim 3$ larger than our results. As the beam size of the IRAM telescope is about half of that of the SMT, the discrepancy of the CO intensity can be explained with different beam dilution effects. Hence, we can conclude that the variation of $\mathrm{CO}$ intensity is relatively small (within 10\%) during the past 15 years. The extremely faint $\mathrm{C}^{17} \mathrm{O}$ emission should be a new detection for this object.

$\mathbf{S i C}_{2} . \mathrm{SiC}_{2}$ has been detected by Woods et al. (2003) in the spectra of CIT 6 through the $\left.\mathrm{SiC}_{2}\left(5_{0,5}-4_{0,4}\right)\right)$ transition at 115.382 $\mathrm{GHz}$. In our line survey, a number of $\mathrm{SiC}_{2}$ transitions were prominently detected at the $2 \mathrm{~mm}$ and $1.3 \mathrm{~mm}$ windows. These lines have a similar profile with an average line width of $\Delta V_{\mathrm{FWHM}}=23.9 \pm 1.9 \mathrm{~km} \mathrm{~s}^{-1}$. We also detected two faint ${ }^{29} \mathrm{SiC}_{2}$ transitions although their intensities are only at a $2-3 \sigma$ noise level. We cannot find previous papers reporting on the detections of these $\mathrm{SiC}_{2}$ and ${ }^{29} \mathrm{SiC}_{2}$ transitions tabulated in Table 1.

CN. CIT 6 is characterized by bright $\mathrm{CN}$ emission. The frequencies of three $\mathrm{CN}(2-1)$ fine-structure groups lie in the region of the SMT spectrum. All of them are clearly seen in Figure 2. The three CN (2-1) fine-structure groups consist of 18 hyperfine structure components. Bachiller et al. (1997) carried out a survey of CN (2-1) and (1-0) emission in a sample of evolved stars. They detected the strongest two CN (2-1) groups in CIT 6. Their observations suggest that the intensity ratio of high- and low-frequency fine-structure groups to be 1.5, in excellent agreement with our result of 1.6.

CS. Strong CS (3-2) emission was detected in the $2 \mathrm{~mm}$ window. This line had previously been discovered by Bujarrabal 

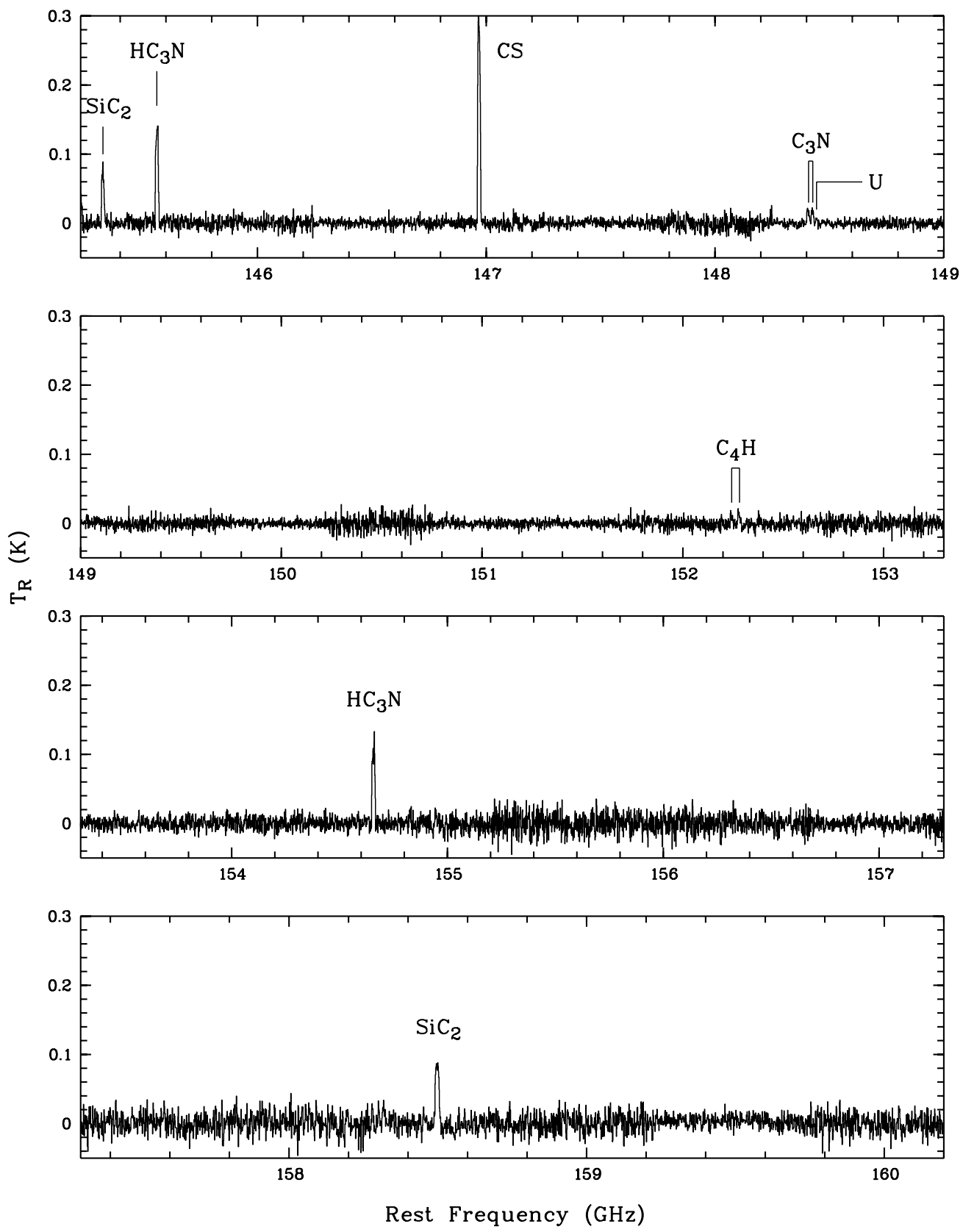

Figure 1. (Continued).

et al. (1994) and Henkel et al. (1985). We also clearly detected its isotopic transitions, ${ }^{13} \mathrm{CS}(3-2,5-4)$ and $\mathrm{C}^{34} \mathrm{~S}(3-2,5-4)$. The faint $C^{33} S(5-4)$ emission was only marginally discovered. The CS (5-4) transition at $244.9 \mathrm{GHz}$ does not lie in the frequency region observed in the work because of a gap between 244.5 and $252.5 \mathrm{GHz}$ in the survey. Figures 3 and 4 show some evidence that the line profiles of CS and its isotopologue emission are slightly asymmetric in shape with a brighter red wing.

SiS. The $J=6-5$ and $J=5-4$ transitions of SiS in CIT 6 have previously been observed by many researchers (Henkel et al. 1985; Bujarrabal et al. 1994; Woods et al. 2003; Schöier et al. 2007). In this work, three SiS transitions with higher $J(8-7,13-12$, and 14-13) were clearly detected with an average line width of $\Delta V_{\mathrm{FWHM}}=22.6 \pm 2.2 \mathrm{~km} \mathrm{~s}^{-1}$.

SiO. $\mathrm{SiO}$ emission in this carbon star has been extensively studied. The transitions observed by previous studies include $J=2-1,3-2,5-4$, and 8-7 (Bujarrabal et al. 1994; Bieging et al. 2000; Woods et al. 2003; Schöier et al. 2006). In this work, we report the detection of the $\mathrm{SiO}(6-5)$ transition and its ${ }^{29} \mathrm{~S}$ and ${ }^{30} \mathrm{~S}$ isotope lines. The $\mathrm{SiO}(6-5)$ line detected in this survey has a similar width to other $\mathrm{SiO}$ transitions detected by previous researchers.

$\mathbf{C}_{2} \mathbf{H}$. The $N=1-0$ transition of $\mathrm{C}_{2} \mathrm{H}$ in this object has been detected by Fukasaku et al. (1994). The $N=3-2$ transition lies in our surveyed frequency range. The rotation transition is split into six hyperfine-structure lines grouped in three fine-structure groups, all of which were detected at the $2 \mathrm{~mm}$ window. The two main components $\left(3_{7 / 2}-2_{5 / 2}\right.$ and $\left.3_{5 / 2}-2_{3 / 2}\right)$ are quite strong and have a well-defined profile, which is similar to that of the CS line with higher flux in the red wing. The $3_{7 / 2}-2_{5 / 2}$ transition is blended with a weak $\mathrm{SiC}_{2}$ line. The $3_{5 / 2}-25 / 2$ transition is too faint to obtain a reliable intensity.

HCN. The $J=3-2$ transitions of $\mathrm{HCN}$ and $\mathrm{H}^{13} \mathrm{CN}$ were clearly detected. The $\mathrm{HCN}$ (3-2) transition is the second 

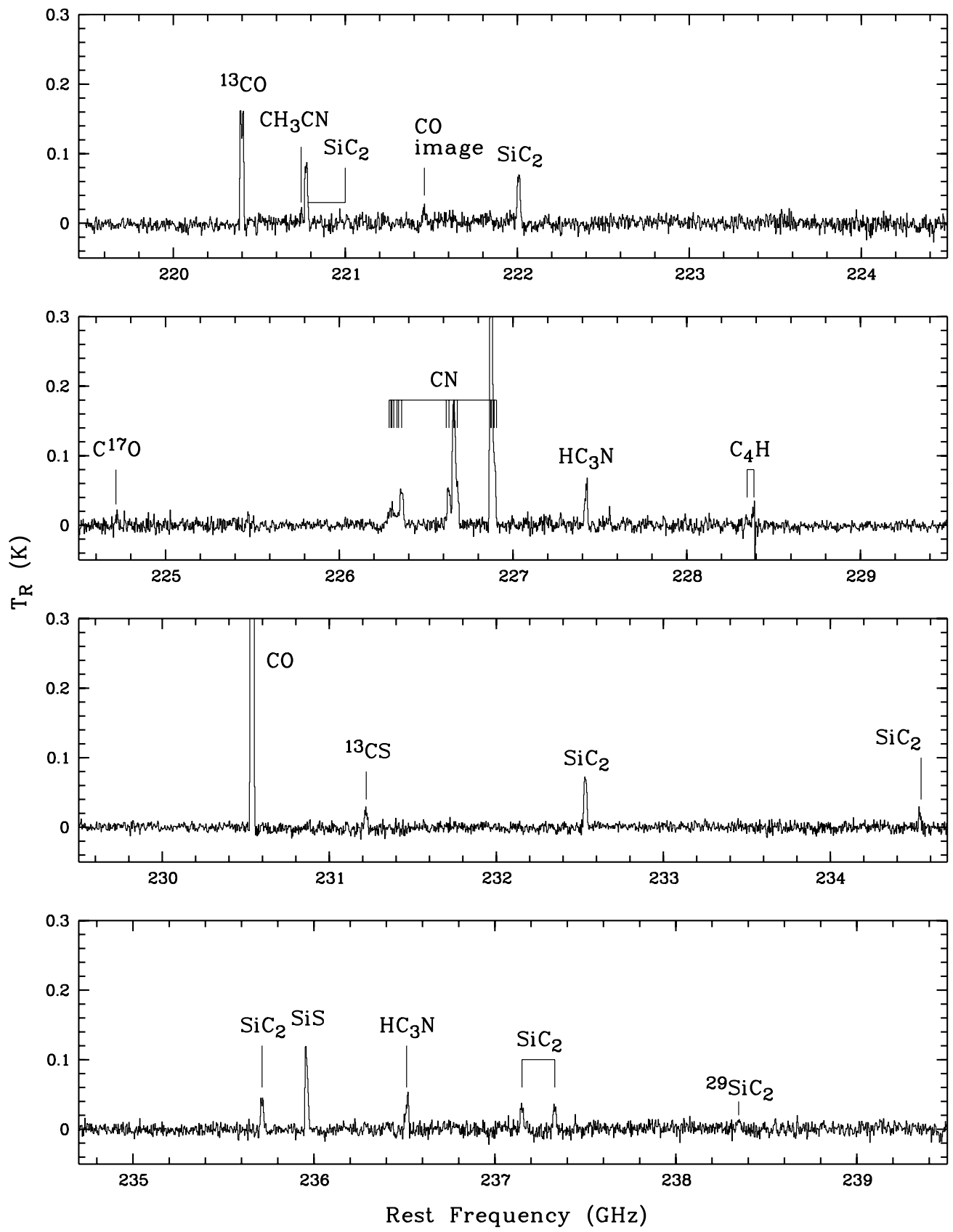

Figure 2. The spectrum of CIT 6 in the frequency ranges $219-244 \mathrm{GHz}$ and $252-268 \mathrm{GHz}$ obtained with the SMT $10 \mathrm{~m}$ telescope. The spectra have been smoothed to a resolution of $3 \mathrm{MHz}$.

brightest line after the $\mathrm{CO}(3-2)$ transition in our survey. This line was first observed by Bieging et al. (2000) using the SMT, who obtained an integrated intensity of $43.1 \mathrm{~K} \mathrm{~km} \mathrm{~s}^{-1}$, which is in excellent agreement with our measurement. Given its line shape, the line should be optically thick. There are five favorable vibrationally excited lines of HCN present in the surveyed frequency range. Three of them were clearly detected, as illustrated in Table 1 . The weak $v_{2}=2^{2 f}, 2^{2 e} J=3-2$ transitions are below the $3 \sigma$ noise level. In CIT $6, \mathrm{HCN}$ is the only species with detected vibrationally excited transitions. Figure 4 shows that these vibrationally excited lines are probably narrower than the $\mathrm{HCN}$ (3-2) line. Discarding the uncertain detection of the $v_{2}=2^{2 f}, 2^{2 e} J=3-2$ transitions and the $v_{2}=1^{1 e} J=3-2$ transition, which is partially blended with the HCN (3-2) line, we obtain the average width of the vibrationally excited lines of $\mathrm{HCN}$ to be $14.2 \mathrm{~K} \mathrm{~km} \mathrm{~s}^{-1}$. The narrow line width of the vibrationally excited lines suggests that they might arise from the hot inner region with a low-expansion velocity. We do not detect the vibrationally excited lines of $\mathrm{H}^{13} \mathrm{CN}$.

$\mathbf{C}_{3}$ N. Fukasaku et al. (1994) and Woods et al. (2003) observed the $\mathrm{C}_{3} \mathrm{~N}(11-10 \mathrm{a}, \mathrm{b})$ transitions in CIT 6 . Both lines are relatively weak. Due to fine-structure interactions, every rotational transition of $\mathrm{C}_{3} \mathrm{~N}$ is split into doublets of a similar intensity. There are $12 \mathrm{C}_{3} \mathrm{~N}$ transitions present in our survey range with six at the $2 \mathrm{~mm}$ window and six at the $1.3 \mathrm{~mm}$ window. We detected the strongest four $\mathrm{C}_{3} \mathrm{~N}$ transitions (14-13 a,b and 15-14 a,b) at the $2 \mathrm{~mm}$ window with $T_{R}>20 \mathrm{mK}$. The $16-15$ a,b transitions at around $158 \mathrm{GHz}$ have a comparable intensity with the other four transitions at the $2 \mathrm{~mm}$ window. However, they fall 

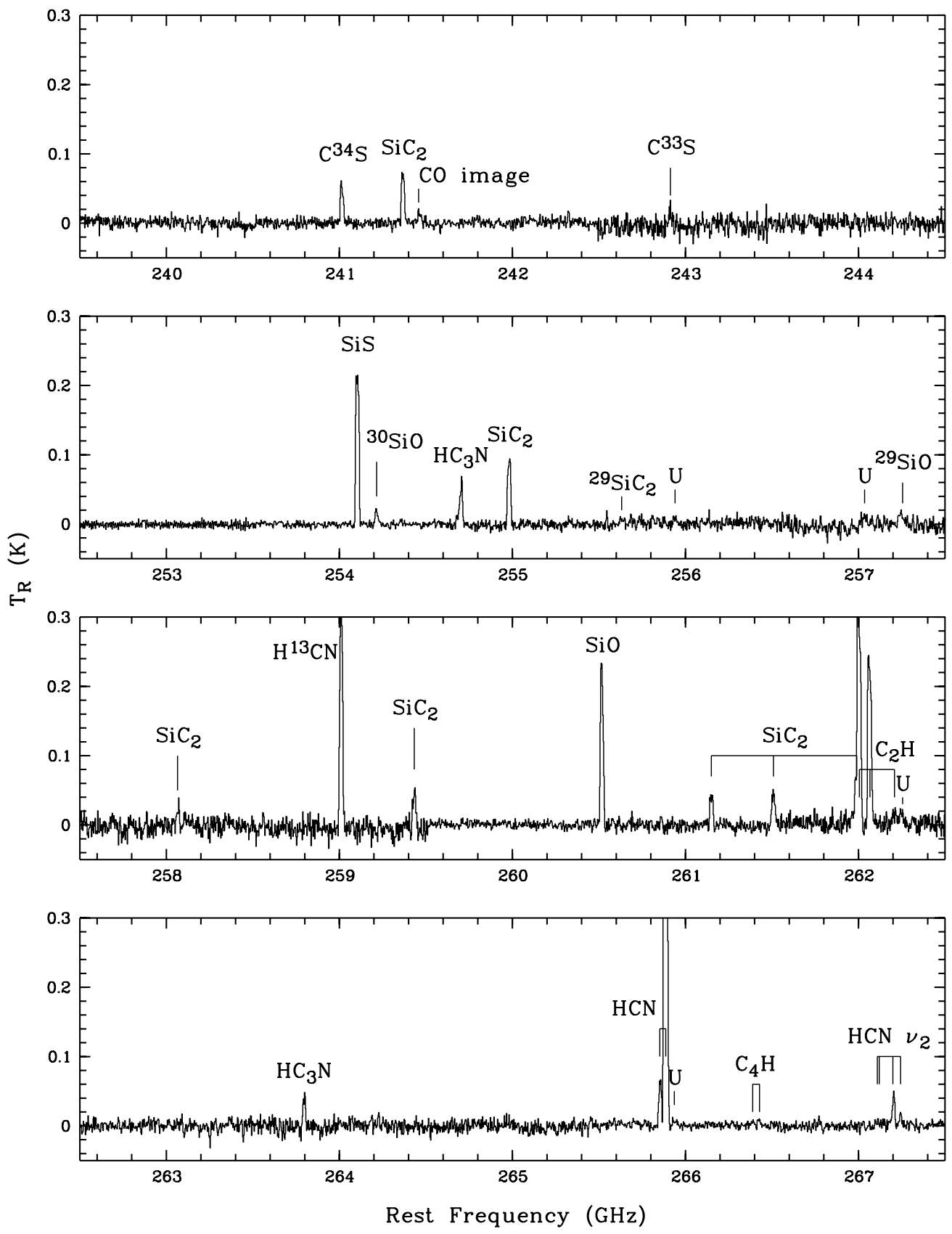

Figure 2. (Continued).

within a spectral region with a high noise level, and thus are not listed in Table. 1.

$\mathbf{C}_{4} \mathbf{H}$. To our knowledge, $\mathrm{C}_{4} \mathrm{H}$ has not been detected in CIT 6 before this work. Fukasaku et al. (1994) and Woods et al. (2003) estimated the intensity upper limits of the $\mathrm{C}_{4} \mathrm{H}(10-9$ a,b) transitions, which indicate that $\mathrm{C}_{4} \mathrm{H}$ emission in this object is relatively weak. Analogous to that of $\mathrm{C}_{3} \mathrm{~N}$, every rotational transition of $\mathrm{C}_{4} \mathrm{H}$ is split into two components with a similar intensity. There are 12 favorable lines of $\mathrm{C}_{4} \mathrm{H}$ present in the frequency range surveyed here. Eight of them were detected with $T_{R}=9-35 \mathrm{mK}$. The $\mathrm{C}_{4} \mathrm{H}(15-14 \mathrm{a}, \mathrm{b})$ and $(16-15 \mathrm{a}, \mathrm{b})$ transitions were clearly detected with well-defined profiles at the $2 \mathrm{~mm}$ window. The $\mathrm{C}_{4} \mathrm{H}(14-13 \mathrm{a}, \mathrm{b})$ lines fall within a spectral region with a high noise level, and thus are not listed in Table 1. The four $\mathrm{C}_{4} \mathrm{H}$ lines (24-23 a,b and 28-27 a,b) at the
$1.3 \mathrm{~mm}$ window are extremely faint, and are only marginally detected. The $\mathrm{C}_{4} \mathrm{H}(25-24 \mathrm{a}, \mathrm{b})$ transitions at around $238 \mathrm{GHz}$ are overwhelmed by noise.

$\mathrm{HC}_{3} \mathbf{N}$. Seven $\mathrm{HC}_{3} \mathrm{~N}$ transitions from $J=15-14$ to $J=29$ 28 are in the frequency range of our survey. All of them were prominently detected with $T_{R}>45 \mathrm{mK}$. Previously only lower $J$ transitions of $\mathrm{HC}_{3} \mathrm{~N}$ have been reported (Henkel et al. 1985; Bujarrabal et al. 1994; Fukasaku et al. 1994; Woods et al. 2003) and to the best of our knowledge all these detections are new. Because of a gap in the $1.3 \mathrm{~mm}$ spectrum, the $\mathrm{HC}_{3} \mathrm{~N}(27-26)$ at $245.606 \mathrm{GHz}$ was not detected here. As shown in Table 1, there is a trend that the widths of $\mathrm{HC}_{3} \mathrm{~N}$ lines decrease with increasing $J$ values, suggesting that the high- $J$ transitions might originate in hot inner regions which have a lower velocity compared to the regions from where the low- $J$ transitions arise. $\mathrm{All}^{\mathrm{HC}_{3} \mathrm{~N} \text { lines }}$ 


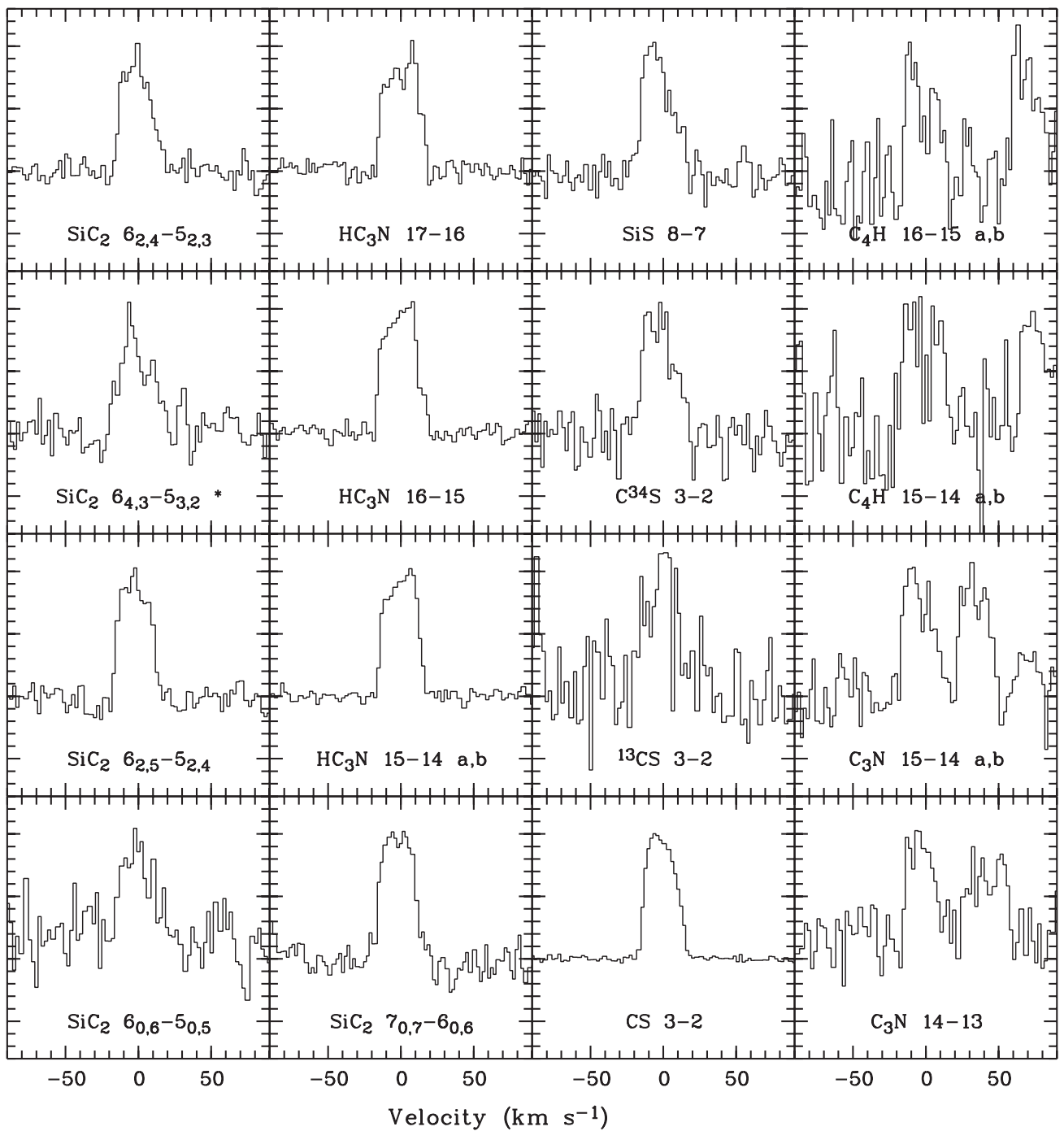

Figure 3. Line profiles of the molecular species detected in the ARO $12 \mathrm{~m}$ spectrum. The spectral resolution is $1 \mathrm{MHz}$. The labeled lines are shown at zero velocity in each panel.

detected in this survey show asymmetric profiles (see Figure 3 and 4). Opposite to $\mathrm{CS}$ and $\mathrm{C}_{2} \mathrm{H}$ lines, $\mathrm{HC}_{3} \mathrm{~N}$ lines have a brighter blue wing relative to the red one. This indicates that the molecular envelope is asymmetric along the line of sight, i.e., the chemical compositions and/or physical conditions in the red and blue sides are different.

$\mathrm{CH}_{3} \mathbf{C N}$. There are 14 favorable $\mathrm{CH}_{3} \mathrm{CN}$ transitions in the survey region. We detected the blended features of the $\left(12_{1}-11_{1}\right)$ and the $\left(12_{0}-11_{0}\right)$ transitions with $T_{R} \sim 23 \mathrm{mK}$, which are the strongest two among the $14 \mathrm{CH}_{3} \mathrm{CN}$ transitions. Woods et al. (2003) failed to detect $\mathrm{CH}_{3} \mathrm{CN}$ in this object and only estimated the intensity upper limit of the $\left(6_{1}-5_{1}\right)$ transition. This is therefore the first detection of $\mathrm{CH}_{3} \mathrm{CN}$ in CIT 6 .

All the lines discovered in this survey have been detected in IRC+10216 (He et al. 2008; Cernicharo et al. 2000). Compared to the spectrum of IRC+10216 in the same frequency range, the nondetected species in the spectrum of CIT 6 include $\mathrm{C}_{3} \mathrm{H}, \quad \mathrm{C}_{3} \mathrm{H}_{2}, \quad \mathrm{C}_{2} \mathrm{~S}, \quad \mathrm{C}_{3} \mathrm{~S}, \quad \mathrm{H}_{2} \mathrm{CO}, \mathrm{SiC}, \mathrm{SiN}, \quad \mathrm{PN}$, and metal-containing molecules, all of which have only weak emission in the spectra of IRC+10216 and thus are below our detection limit. A number of vibrationally excited species have been detected in IRC+10216 (see Cernicharo et al. 2000, and the references therein). For CIT 6, however, no vibrationally excited lines except those of HCN are strong enough to be detected. Moreover, we find no evidence for the presence of ionic species in CIT 6.

\subsection{Rotation-Diagram Analysis and Fractional Abundances}

The standard "rotation-diagram" method was applied to calculate the excitation temperatures $\left(T_{\text {ex }}\right)$ and column densities $(N)$ of the molecules observed in our spectra. From the equation of radiative transfer and assuming that the lines are optically thin, the level populations are in local thermal equilibrium (LTE), and $T_{\mathrm{ex}}>>T_{\mathrm{bg}}$, where $T_{\mathrm{bg}}$ is the cosmic background radiation temperature $(2.7 \mathrm{~K})$, we have the well known relation

$$
\ln \frac{N_{u}}{g_{u}}=\ln \frac{3 k \int T_{s} d v}{8 \pi^{3} v S \mu^{2}}=\ln \frac{N}{Q\left(T_{\mathrm{ex}}\right)}-\frac{E_{u}}{k T_{\mathrm{ex}}} .
$$

$N_{u}, g_{u}$, and $E_{u}$ are the population, degeneracy, and excitation energy of the upper level, $\int T_{s} d v$ is the integration of the source brightness temperature over the velocity, $S$ is the line strength, $\mu$ is the dipole moment, $v$ is the line frequency, and $Q$ is the rotational partition function. If several transitions arising from levels covering a wide energy range are observed, $T_{\text {ex }}$ and $N$ can be deduced using a straight-line fit to $N_{u} / g_{u}$ versus $E_{u} / k T_{\mathrm{ex}}$. 


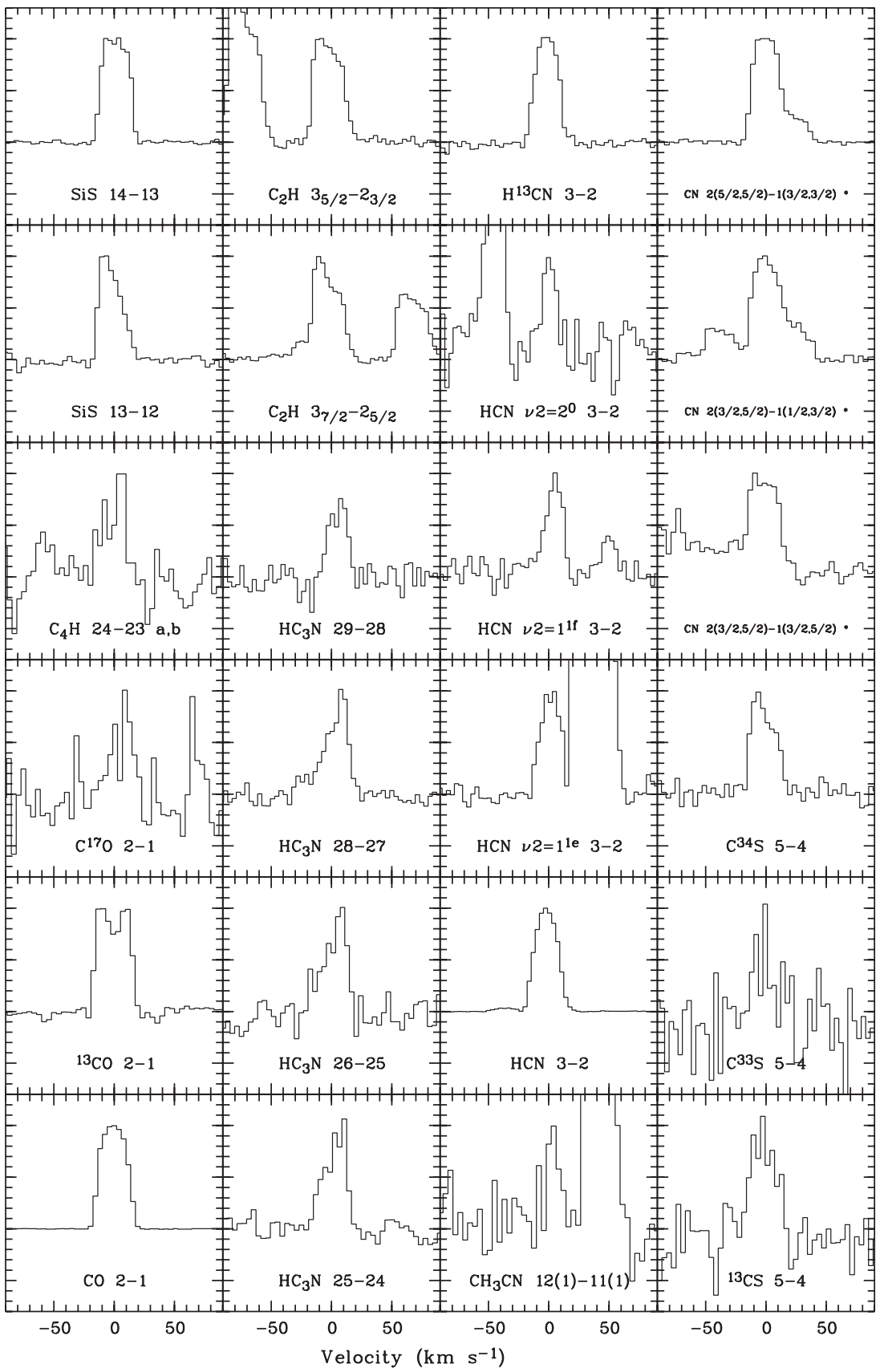

Figure 4. Line profiles of the molecular species detected in the SMT spectrum. The spectral resolution is $3 \mathrm{MHz}$. The labeled lines are shown at zero velocity in each panel.

The rotation diagram provides important tools for studies of excitation conditions. Departure from the linear relation can be caused by different excitation mechanisms or misidentification. For $\mathrm{SiC}_{2}, \mathrm{SiS}, \mathrm{HC}_{3} \mathrm{~N}$, and $\mathrm{C}_{4} \mathrm{H}$, there are adequate numbers of detected transitions covering a wide range of excitation energy; their rotation diagrams are given in Figure 5. Good linear correlations were obtained for these species. For the calculations, we have corrected the effect of beam dilution through $T_{s}=T_{R}\left(\theta_{b}^{2}+\theta_{s}^{2}\right) / \theta_{s}^{2}$, where $\theta_{b}$ is the antenna full beam at half-power $\left(\sim 40^{\prime \prime}\right.$ and $30^{\prime \prime}$ for the ARO $12 \mathrm{~m}$ and the SMT, respectively) and $\theta_{s}$ is the source diameter (which may be different for different species). We followed the assumption by Fukasaku et al. (1994) and took a common $\theta_{s}$ of $20^{\prime \prime}$ for all the species. Since the source size is likely to vary from species to species
(Lindqvist et al. 2000), this assumption will introduce a $\sim 50 \%$ uncertainty in the derived column densities. The derived excitation temperatures and column densities are given in Table 3. For these species for which only one line was detected or observed transitions arise from a narrow range of energy levels, the method of the rotation-diagram method cannot be employed and a constant $T_{\mathrm{ex}}$ of $40 \mathrm{~K}$ was assumed for the calculations of their column densities.

Assuming that the molecular envelope is a spherical shell, the emission is optically thin, $T_{\mathrm{ex}}$ is uniform throughout the envelope, mass loss rate and expansion velocity are constant during the formation of the envelope, and the molecular density follows an $r^{-2}$ law, we determined the fractional abundances of the observed species with respect to $\mathrm{H}_{2}$ through the formula 


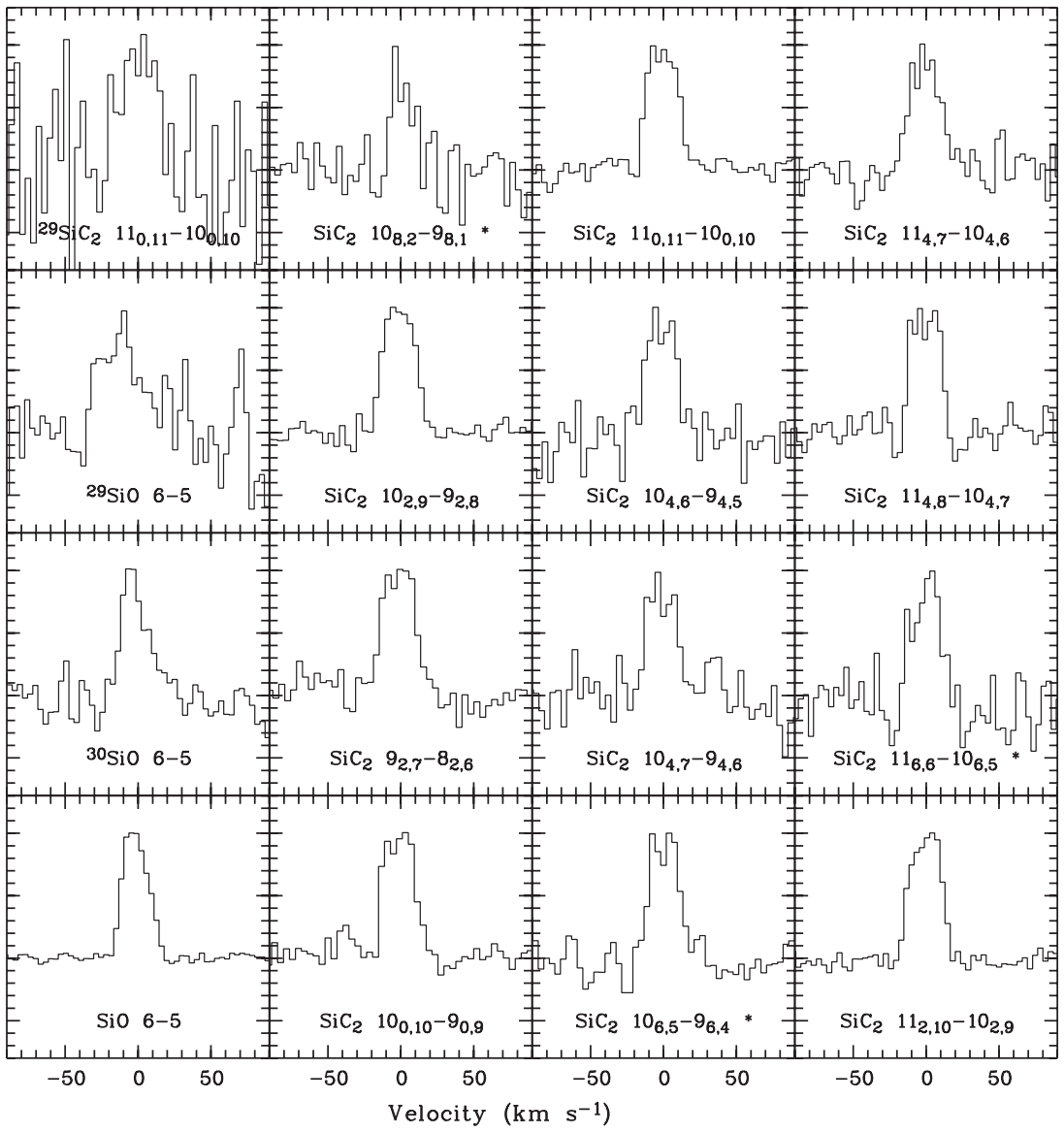

Figure 4. (Continued).
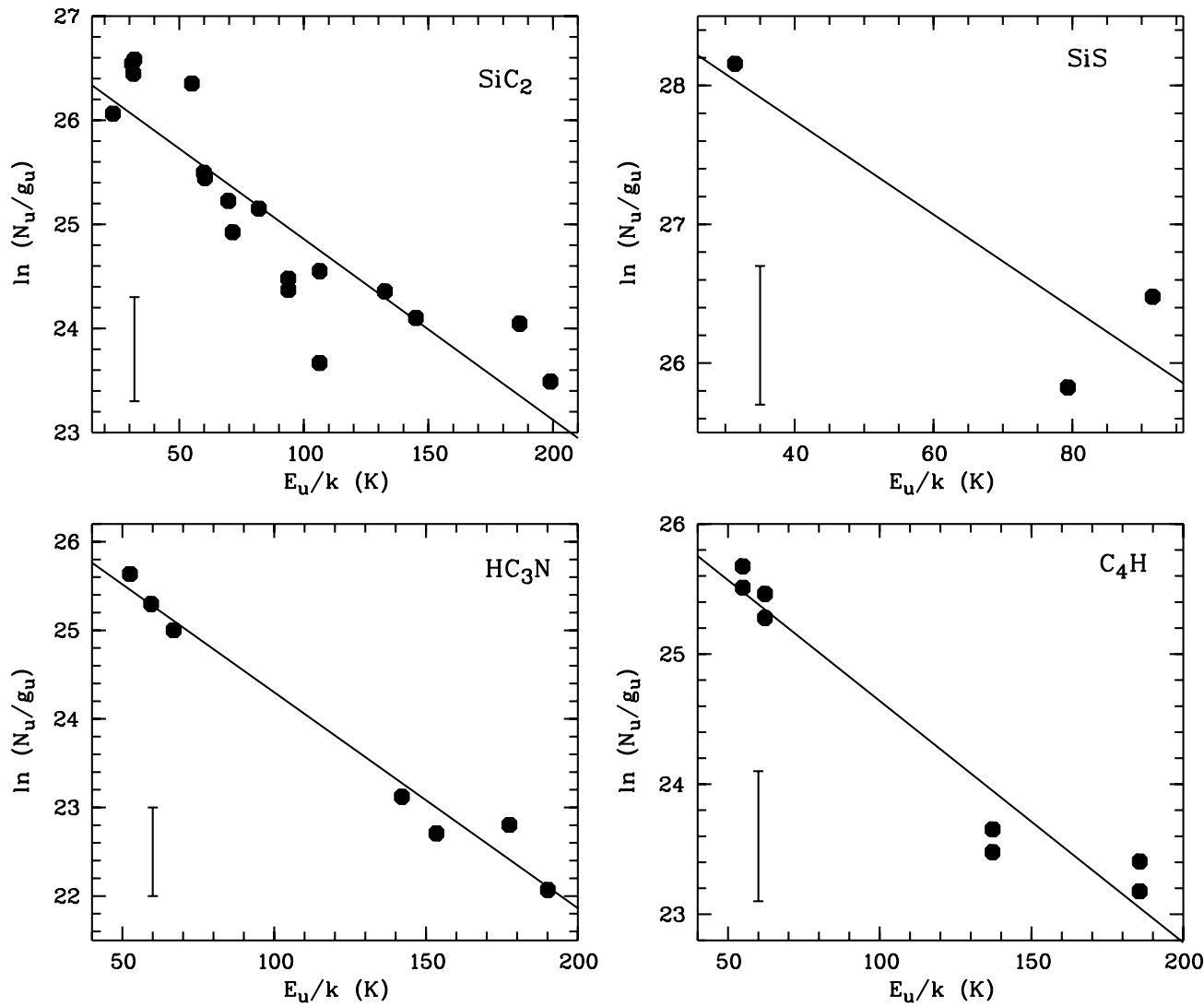

Figure 5. Rotational diagrams for the detected species in CIT 6. Error bars are given on the lower left. 
Table 1

Molecular Transitions Detected in CIT 6

\begin{tabular}{|c|c|c|c|c|c|c|c|}
\hline $\begin{array}{l}\text { Frequency } \\
\text { (MHz) }\end{array}$ & Species & $\begin{array}{c}\text { Transition } \\
\text { (upper-lower) }\end{array}$ & $\begin{array}{l}\mathrm{rms} \\
(\mathrm{mK})\end{array}$ & $\begin{array}{l}T_{\mathrm{R}} \\
(\mathrm{K})\end{array}$ & $\begin{array}{c}\int T_{\mathrm{R}} \mathrm{d} v \\
\left(\mathrm{~K} \mathrm{~km} \mathrm{~s}^{-1}\right)\end{array}$ & $\begin{array}{l}\Delta V_{\mathrm{FWHM}} \\
\left(\mathrm{km} \mathrm{s}^{-1}\right) \\
\end{array}$ & Remarks $^{\mathrm{a}}$ \\
\hline 230538.0 & $\mathrm{CO}$ & $J=2-1$ & 4.2 & 2.555 & 67.590 & 23.7 & \\
\hline 220398.7 & ${ }^{13} \mathrm{CO}$ & $J=2-1$ & 5.6 & 0.163 & 4.996 & 29.0 & \\
\hline 224714.4 & $\mathrm{C}^{17} \mathrm{O}$ & $J=2-1$ & 7.1 & 0.022 & 0.258 & 25.6 & \\
\hline 137180.8 & $\mathrm{SiC}_{2}$ & $6_{0,6}-5_{0,5}$ & 6.8 & 0.040 & 1.040 & 24.2 & \\
\hline 140920.1 & $\mathrm{SiC}_{2}$ & $6_{2,5}-5_{2,4}$ & 4.8 & 0.062 & 1.459 & 22.6 & \\
\hline 141751.5 & $\mathrm{SiC}_{2}$ & $6_{4,3}-5_{3,2}$ & 6.1 & 0.073 & 1.671 & 23.4 & * \\
\hline 141755.4 & $\mathrm{SiC}_{2}$ & $64,2-54,1$ & $\ldots$ & $\ldots$ & $\ldots$ & $\ldots$ & $*$ \\
\hline 145325.8 & $\mathrm{SiC}_{2}$ & $6_{2,4}-5_{2,3}$ & 6.5 & 0.088 & 1.867 & 21.1 & \\
\hline 158499.2 & $\mathrm{SiC}_{2}$ & $7_{0,7}-6_{0,6}$ & 9.5 & 0.086 & 2.548 & 25.3 & \\
\hline 220773.7 & $\mathrm{SiC}_{2}$ & $10_{0,10}-9_{0,9}$ & 5.6 & 0.087 & 2.282 & 22.8 & \\
\hline 222009.4 & $\mathrm{SiC}_{2}$ & $9_{2,7}-8_{2,6}$ & 6.4 & 0.069 & 1.887 & 24.8 & \\
\hline 232534.1 & $\mathrm{SiC}_{2}$ & $10_{2,9}-9_{2,8}$ & 4.0 & 0.072 & 1.937 & 25.2 & \\
\hline 234534.0 & $\mathrm{SiC}_{2}$ & $10_{8,2}-98,1$ & 4.8 & 0.030 & 0.452 & 16.1 & $*$ \\
\hline 234534.0 & $\mathrm{SiC}_{2}$ & $10_{8,3}-9_{8,2}$ & $\ldots$ & $\ldots$ & $\ldots$ & $\ldots$ & $*$ \\
\hline 235713.0 & $\mathrm{SiC}_{2}$ & $10_{6,5}-9_{6,4}$ & 5.2 & 0.045 & 1.101 & 25.2 & $*$ \\
\hline 235713.1 & $\mathrm{SiC}_{2}$ & $10_{6,4}-9_{6,3}$ & $\ldots$ & $\ldots$ & $\ldots$ & $\ldots$ & $*$ \\
\hline 237150.0 & $\mathrm{SiC}_{2}$ & $10_{4,7}-9_{4,6}$ & 5.8 & 0.038 & 0.859 & 20.7 & \\
\hline 237331.3 & $\mathrm{SiC}_{2}$ & $10_{4,6}-94,5$ & 5.8 & 0.036 & 0.771 & 23.5 & \\
\hline 241367.7 & $\mathrm{SiC}_{2}$ & $11_{0,11}-10_{0,10}$ & 4.2 & 0.074 & 1.770 & 22.7 & \\
\hline 254981.5 & $\mathrm{SiC}_{2}$ & $11_{2,10}-10_{2,9}$ & 3.9 & 0.094 & 2.448 & 23.6 & \\
\hline 258065.0 & $\mathrm{SiC}_{2}$ & $11_{8,3}-10_{8,2}$ & 9.3 & 0.039 & 0.471 & 10.5 & $*$ \\
\hline 258065.0 & $\mathrm{SiC}_{2}$ & $11_{8,4}-10_{8,3}$ & $\ldots$ & $\ldots$ & $\ldots$ & $\ldots$ & $*$ \\
\hline 259433.3 & $\mathrm{SiC}_{2}$ & $11_{6,6}-10_{6,5}$ & 7.8 & 0.054 & 1.301 & 27.5 & $*$ \\
\hline 259433.3 & $\mathrm{SiC}_{2}$ & $11_{6,5}-10_{6,4}$ & $\ldots$ & $\ldots$ & $\ldots$ & $\ldots$ & $*$ \\
\hline 261150.7 & $\mathrm{SiC}_{2}$ & $11_{4,8}-10_{4,7}$ & 4.1 & 0.044 & 1.049 & 21.5 & \\
\hline 261509.3 & $\mathrm{SiC}_{2}$ & $11_{4,7}-10_{4,6}$ & 4.1 & 0.051 & 1.270 & 26.5 & \\
\hline 261990.7 & $\mathrm{SiC}_{2}$ & $12_{0,12}-11_{0,11}$ & 7.1 & 0.387 & 9.945 & 26.1 & $\$$ \\
\hline 238347.0 & ${ }^{29} \mathrm{SiC}_{2}$ & $11_{0,11}-10_{0,10}$ & 5.3 & 0.013 & 0.366 & 35.3 & \\
\hline 255631.6 & ${ }^{29} \mathrm{SiC}_{2}$ & $11_{6,6}-10_{6,5}$ & 4.2 & 0.010 & 0.127 & 32.9 & $*$ \\
\hline 255631.8 & ${ }^{29} \mathrm{SiC}_{2}$ & $11_{6,5}-10_{6,4}$ & $\ldots$ & $\ldots$ & $\ldots$ & $\ldots$ & $*$ \\
\hline 226287.4 & $\mathrm{CN}$ & $N(J, F)=2(3 / 2,1 / 2)-1(3 / 2,1 / 2)$ & 4.9 & 0.034 & 1.278 & 53.0 & $*$ \\
\hline 226298.9 & $\mathrm{CN}$ & $N(J, F)=2(3 / 2,1 / 2)-1(3 / 2,3 / 2)$ & $\ldots$ & $\ldots$ & $\ldots$ & $\ldots$ & $*$ \\
\hline 226303.0 & $\mathrm{CN}$ & $N(J, F)=2(3 / 2,3 / 2)-1(3 / 2,1 / 2)$ & $\ldots$ & $\ldots$ & $\ldots$ & $\ldots$ & $*$ \\
\hline 226314.5 & $\mathrm{CN}$ & $N(J, F)=2(3 / 2,3 / 2)-1(3 / 2,3 / 2)$ & $\ldots$ & $\ldots$ & $\ldots$ & $\ldots$ & $*$ \\
\hline 226332.5 & $\mathrm{CN}$ & $N(J, F)=2(3 / 2,3 / 2)-1(3 / 2,5 / 2)$ & 4.9 & 0.052 & 1.819 & 25.6 & * \\
\hline 226341.9 & $\mathrm{CN}$ & $N(J, F)=2(3 / 2,5 / 2)-1(3 / 2,3 / 2)$ & $\ldots$ & $\ldots$ & $\ldots$ & $\ldots$ & * \\
\hline 226359.9 & $\mathrm{CN}$ & $N(J, F)=2(3 / 2,5 / 2)-1(3 / 2,5 / 2)$ & $\ldots$ & $\ldots$ & $\ldots$ & $\ldots$ & $*$ \\
\hline 226616.6 & $\mathrm{CN}$ & $N(J, F)=2(3 / 2,1 / 2)-1(1 / 2,3 / 2)$ & 4.9 & 0.053 & 1.593 & 26.8 & $*$ \\
\hline 226632.2 & $\mathrm{CN}$ & $N(J, F)=2(3 / 2,3 / 2)-1(1 / 2,3 / 2)$ & $\ldots$ & $\ldots$ & $\ldots$ & $\ldots$ & * \\
\hline 226659.6 & $\mathrm{CN}$ & $N(J, F)=2(3 / 2,5 / 2)-1(1 / 2,3 / 2)$ & 4.9 & 0.178 & 6.092 & 29.3 & $*$ \\
\hline 226663.7 & $\mathrm{CN}$ & $N(J, F)=2(3 / 2,1 / 2)-1(1 / 2,1 / 2)$ & $\ldots$ & $\ldots$ & $\ldots$ & $\ldots$ & $*$ \\
\hline 226679.3 & $\mathrm{CN}$ & $N(J, F)=2(3 / 2,3 / 2)-1(1 / 2,1 / 2)$ & $\ldots$ & $\ldots$ & $\ldots$ & $\ldots$ & $*$ \\
\hline 226874.2 & $\mathrm{CN}$ & $N(J, F)=2(5 / 2,5 / 2)-1(3 / 2,3 / 2)$ & 4.9 & 0.394 & 12.176 & 24.6 & $*$ \\
\hline 226874.8 & $\mathrm{CN}$ & $N(J, F)=2(5 / 2,7 / 2)-1(3 / 2,5 / 2)$ & $\ldots$ & $\ldots$ & $\ldots$ & $\ldots$ & $*$ \\
\hline 226875.9 & $\mathrm{CN}$ & $N(J, F)=2(5 / 2,3 / 2)-1(3 / 2,1 / 2)$ & $\ldots$ & $\ldots$ & $\ldots$ & $\ldots$ & * \\
\hline 226887.4 & $\mathrm{CN}$ & $N(J, F)=2(5 / 2,3 / 2)-1(3 / 2,3 / 2)$ & $\ldots$ & $\ldots$ & $\ldots$ & $\ldots$ & * \\
\hline 226892.1 & $\mathrm{CN}$ & $N(J, F)=2(5 / 2,5 / 2)-1(3 / 2,5 / 2)$ & $\ldots$ & $\ldots$ & $\ldots$ & $\ldots$ & * \\
\hline 226905.4 & $\mathrm{CN}$ & $N(J, F)=2(5 / 2,3 / 2)-1(3 / 2,5 / 2)$ & $\ldots$ & $\ldots$ & $\ldots$ & $\ldots$ & $*$ \\
\hline 146969.0 & $\mathrm{CS}$ & $J=3-2$ & 4.8 & 0.303 & 7.058 & 21.6 & \\
\hline 138739.3 & ${ }^{13} \mathrm{CS}$ & $J=3-2$ & 4.6 & 0.023 & 0.495 & 21.0 & \\
\hline 231221.0 & ${ }^{13} \mathrm{CS}$ & $J=5-4$ & 5.0 & 0.027 & 0.846 & 27.6 & \\
\hline 242913.6 & $\mathrm{C}^{33} \mathrm{~S}$ & $J=5-4$ & 7.4 & 0.032 & 0.563 & 12.4 & \\
\hline 144617.1 & $\mathrm{C}^{34} \mathrm{~S}$ & $J=3-2$ & 4.9 & 0.040 & 1.039 & 26.1 & \\
\hline 241016.1 & $\mathrm{C}^{34} \mathrm{~S}$ & $J=5-4$ & 4.6 & 0.062 & 1.315 & 23.1 & \\
\hline 145227.0 & $\mathrm{SiS}$ & $J=8-7$ & 6.5 & 0.067 & 1.745 & 22.1 & \\
\hline 235961.1 & $\mathrm{SiS}$ & $J=13-12$ & 5.2 & 0.119 & 2.598 & 20.6 & \\
\hline 254102.9 & $\mathrm{SiS}$ & $J=14-13$ & 3.6 & 0.213 & 5.791 & 25.0 & \\
\hline 260518.0 & $\mathrm{SiO}$ & $J=6-5$ & 4.8 & 0.233 & 5.233 & 20.3 & \\
\hline 254216.7 & ${ }^{30} \mathrm{SiO}$ & $J=6-5$ & 3.6 & 0.022 & 0.581 & 21.5 & \\
\hline 257255.2 & ${ }^{29} \mathrm{SiO}$ & $J=6-5$ & 6.9 & 0.021 & 0.583 & 30.3 & \\
\hline 262005.3 & $\mathrm{C}_{2} \mathrm{H}$ & $N_{\mathrm{J}}=3_{7 / 2}-2_{5 / 2}$ & 7.1 & 0.387 & 9.945 & 26.1 & $\$$ \\
\hline 262066.1 & $\mathrm{C}_{2} \mathrm{H}$ & $N_{\mathrm{J}}=3_{5 / 2}-2_{3 / 2}$ & 7.1 & 0.244 & 6.596 & 25.4 & \\
\hline 262208.4 & $\mathrm{C}_{2} \mathrm{H}$ & $N_{\mathrm{J}}=3_{5 / 2}-2_{5 / 2}$ & 6.0 & 0.024 & 0.539 & 22.9 & \\
\hline 265886.4 & $\mathrm{HCN}$ & $J=3-2$ & 3.7 & 1.959 & 43.942 & 21.2 & \\
\hline
\end{tabular}


Table 1

(Continued)

\begin{tabular}{|c|c|c|c|c|c|c|c|}
\hline $\begin{array}{l}\text { Frequency } \\
(\mathrm{MHz})\end{array}$ & Species & $\begin{array}{c}\text { Transition } \\
\text { (upper-lower) }\end{array}$ & $\begin{array}{l}\mathrm{rms} \\
(\mathrm{mK})\end{array}$ & $\begin{array}{l}T_{\mathrm{R}} \\
(\mathrm{K}) \\
\end{array}$ & $\begin{array}{c}\int T_{\mathrm{R}} \mathrm{d} v \\
\left(\mathrm{~K} \mathrm{~km} \mathrm{~s}^{-1}\right)\end{array}$ & $\begin{array}{l}\Delta V_{\mathrm{FWHM}} \\
\left(\mathrm{km} \mathrm{s}^{-1}\right) \\
\end{array}$ & Remarks $^{\mathrm{a}}$ \\
\hline 265852.8 & $\mathrm{HCN}$ & $v_{2}=1^{1 e} J=3-2$ & 3.7 & 0.067 & 1.392 & 20.4 & \\
\hline 267109.1 & $\mathrm{HCN}$ & $v_{2}=2^{2 f} J=3-2$ & 4.2 & 0.011 & 0.098 & 22.5 & $*$ \\
\hline 267120.1 & $\mathrm{HCN}$ & $v_{2}=2^{2 e} J=3-2$ & $\ldots$ & $\ldots$ & $\ldots$ & $\ldots$ & $*$ \\
\hline 267199.3 & $\mathrm{HCN}$ & $\nu_{2}=1^{1 f} J=3-2$ & 4.2 & 0.050 & 0.876 & 14.4 & \\
\hline 267243.2 & $\mathrm{HCN}$ & $v_{2}=2^{0} J=3-2$ & 4.2 & 0.020 & 0.318 & 14.0 & \\
\hline 259011.8 & $\mathrm{H}^{13} \mathrm{CN}$ & $J=3-2$ & 9.6 & 0.296 & 7.120 & 20.8 & \\
\hline 138515.7 & $\mathrm{C}_{3} \mathrm{~N}$ & $N=14-13 \mathrm{a}$ & 7.3 & 0.039 & 0.747 & 21.5 & \\
\hline 138534.5 & $\mathrm{C}_{3} \mathrm{~N}$ & $N=14-13 \mathrm{~b}$ & 7.3 & 0.031 & 0.674 & 25.5 & \\
\hline 148409.1 & $\mathrm{C}_{3} \mathrm{~N}$ & $N=15-14 \mathrm{a}$ & 4.2 & 0.021 & 0.537 & 29.9 & \\
\hline 148427.8 & $\mathrm{C}_{3} \mathrm{~N}$ & $N=15-14 \mathrm{~b}$ & 4.2 & 0.021 & 0.521 & 35.6 & \\
\hline 142728.8 & $\mathrm{C}_{4} \mathrm{H}$ & $N=15-14 \mathrm{a}$ & 6.0 & 0.022 & 0.567 & 33.7 & \\
\hline 142767.3 & $\mathrm{C}_{4} \mathrm{H}$ & $N=15-14 \mathrm{~b}$ & 6.0 & 0.021 & 0.450 & 23.1 & \\
\hline 152243.6 & $\mathrm{C}_{4} \mathrm{H}$ & $N=16-15 \mathrm{a}$ & 5.7 & 0.018 & 0.433 & 23.6 & \\
\hline 152282.1 & $\mathrm{C}_{4} \mathrm{H}$ & $N=16-15 \mathrm{~b}$ & 5.7 & 0.020 & 0.505 & 27.2 & \\
\hline 228348.6 & $\mathrm{C}_{4} \mathrm{H}$ & $N=24-23 \mathrm{a}$ & 4.1 & 0.015 & 0.224 & 19.7 & \\
\hline 228387.0 & $\mathrm{C}_{4} \mathrm{H}$ & $N=24-23 \mathrm{~b}$ & 4.1 & 0.035 & 0.256 & 13.1 & \\
\hline 266389.9 & $\mathrm{C}_{4} \mathrm{H}$ & $N=28-27 \mathrm{a}$ & 3.9 & 0.008 & 0.140 & 29.9 & \\
\hline 266428.2 & $\mathrm{C}_{4} \mathrm{H}$ & $N=28-27 \mathrm{~b}$ & 3.9 & 0.009 & 0.175 & 19.1 & \\
\hline 136464.4 & $\mathrm{HC}_{3} \mathrm{~N}$ & $J=15-14$ & 6.6 & 0.160 & 4.131 & 24.0 & \\
\hline 145560.9 & $\mathrm{HC}_{3} \mathrm{~N}$ & $J=16-15$ & 6.5 & 0.139 & 3.772 & 24.1 & \\
\hline 154657.3 & $\mathrm{HC}_{3} \mathrm{~N}$ & $J=17-16$ & 7.0 & 0.131 & 3.165 & 24.4 & \\
\hline 227418.9 & $\mathrm{HC}_{3} \mathrm{~N}$ & $J=25-24$ & 6.3 & 0.064 & 1.404 & 22.0 & \\
\hline 236512.8 & $\mathrm{HC}_{3} \mathrm{~N}$ & $J=26-25$ & 6.2 & 0.053 & 1.078 & 21.7 & \\
\hline 254699.5 & $\mathrm{HC}_{3} \mathrm{~N}$ & $J=28-27$ & 3.9 & 0.068 & 1.160 & 21.7 & \\
\hline 263792.3 & $\mathrm{HC}_{3} \mathrm{~N}$ & $J=29-28$ & 7.9 & 0.048 & 0.990 & 19.6 & \\
\hline 220743.0 & $\mathrm{CH}_{3} \mathrm{CN}$ & $12(1)-11(1)$ & 5.6 & 0.023 & 0.290 & 17.6 & $*$ \\
\hline 220747.2 & $\mathrm{CH}_{3} \mathrm{CN}$ & $12(0)-11(0)$ & $\ldots$ & $\ldots$ & $\ldots$ & $\ldots$ & $*$ \\
\hline
\end{tabular}

Note. ${ }^{\text {a }}$ Represents unsolved hyperfine structure lines; \$ represents those blended with other species.

Table 2

Unidentified Lines

\begin{tabular}{lcccc}
\hline \hline $\begin{array}{l}\text { Frequency } \\
(\mathrm{MHz})\end{array}$ & $\begin{array}{c}\mathrm{rms} \\
(\mathrm{mK})\end{array}$ & $\begin{array}{c}T_{\mathrm{R}} \\
(\mathrm{K})\end{array}$ & $\begin{array}{c}\int T_{\mathrm{R}} \mathrm{d} v \\
\left(\mathrm{~K} \mathrm{~km} \mathrm{~s}^{-1}\right)\end{array}$ & $\begin{array}{c}\Delta V_{\mathrm{FWHM}} \\
\left(\mathrm{km} \mathrm{s}^{-1}\right)\end{array}$ \\
\hline 148444 & 4.5 & 0.008 & 0.249 & 14.8 \\
257035 & 7.1 & 0.015 & 0.442 & 38.6 \\
255940 & 4.9 & 0.012 & 0.207 & 29.4 \\
262255 & 6.0 & 0.022 & 0.501 & 26.7 \\
265936 & 3.7 & 0.012 & 0.214 & 37.3 \\
\hline
\end{tabular}

proposed by Olofsson (1996),

$$
f_{\mathrm{X}}=1.7 \times 10^{-28} \frac{v_{e} \theta_{b} D}{\dot{M}_{\mathrm{H}_{2}}} \frac{Q\left(T_{\mathrm{ex}}\right) v_{u l}^{2}}{g_{u} A_{u l}} \frac{e^{E_{l} / k T_{\mathrm{ex}}} \int T_{R} d v}{\int_{x_{i}}^{x_{e}} e^{-4 \ln 2 x^{2}} d x},
$$

where $\int T_{R} d v$ is given in $\mathrm{K} \mathrm{km} \mathrm{s}{ }^{-1}$, the full half-power beamwidth $\theta_{b}$ is in arcsec, the expansion velocity $v_{e}$ is in $\mathrm{km} \mathrm{s}^{-1}$, $D$ is the distance in pc, $\dot{M}_{\mathrm{H}_{2}}$ is the mass loss rate in $M_{\odot} \mathrm{yr}^{-1}, v_{u l}$ is the line frequency in $\mathrm{GHz}, g_{u}$ is the statistical weight of the upper level, $A_{u l}$ is the Einstein coefficient for the transition, $E_{l}$ is the energy of the lower level, and $x_{i, e}=R_{i, e} /\left(\theta_{b} D\right)$ with $R_{i}$ and $R_{e}$ being the inner radius and outer radius of the shell. For the calculations, we adopted $D=400 \mathrm{pc}$ (Cohen \& Hitchon 1996).

For the determination of molecular abundances using Equation (2), we first derive the expansion velocity $v_{e}=18 \mathrm{~km} \mathrm{~s}^{-1}$ from the profile of the CO (2-1) line. The mass-loss rate of $\dot{M}_{\mathrm{H}_{2}}=3.2 \times 10^{-6} M_{\odot} \mathrm{yr}^{-1}$ is obtained by applying Equation (2) of Winters et al. (2002) to the CO (2-1) line assuming $f_{\mathrm{CO}}=1 \times 10^{-3}$. These values of $v_{e}$ and $\dot{M}_{\mathrm{H}_{2}}$ are in excellent agreement with those given by Fukasaku et al.
(1994). These parameters suggest that CIT 6 has a similar expansion velocity and about one order of magnitude lower mass loss rate in comparison with IRC+10216.

The resultant abundances are given in Table 3 . Combined with the uncertainties introduced by calibration, noise, baseline, and source size, we estimate that the errors of the column densities and abundances amount to a factor of $\sim 2$. One should bear in mind that when the emission is optically thick, the $N$ and $f_{\mathrm{X}}$ listed in Table 3 represent only lower limits. A comparison of our results with those derived by Fukasaku et al. (1994) and Woods et al. (2003) is also given in Table 3 and no significant discrepancies are found.

\section{DISCUSSION}

\subsection{Chemistry}

\subsubsection{Oxygen-Bearing Molecules}

Similar to IRC+10216, the molecular envelope of CIT 6 is also characterized by a lack of oxygen-bearing compounds and abundance of carbon-bearing compounds. In IRC+10216, three O-bearing molecules are observed, $\mathrm{CO}, \mathrm{SiO}$, and $\mathrm{HCO}^{+}$(Cernicharo et al. 2000), whereas in CIT 6, only two O-bearing molecules $(\mathrm{CO}$ and $\mathrm{SiO})$ are detected. We find that the $\mathrm{SiO}(6-5) /{ }^{13} \mathrm{CO}(2-1)$ integrated intensity ratio in CIT 6 is 1.05 , in excellent agreement with the value of 1.13 in IRC+10216 (He et al. 2008). In our discussion, ${ }^{13} \mathrm{CO}$ is taken as a reference molecule because the ${ }^{13} \mathrm{CO}(2-1)$ line is likely optically thin and the ${ }^{12} \mathrm{C} /{ }^{13} \mathrm{C}$ isotopic ratios are similar in CIT 6 and IRC+10216 (see Section 4.2). SiO has been commonly detected in C-rich envelopes (Schöier et al. 2006), implying 
Table 3

Excitation Temperatures, Column Densities, and Abundances with Respect to $\mathrm{H}_{2}{ }^{\text {a }}$

\begin{tabular}{|c|c|c|c|c|c|}
\hline \multirow[t]{2}{*}{ Species } & \multirow[t]{2}{*}{$T_{\mathrm{ex}}(\mathrm{K})^{\mathrm{b}}$} & \multicolumn{2}{|c|}{$N\left(\mathrm{~cm}^{-2}\right)$} & \multicolumn{2}{|c|}{$f_{\mathrm{X}}$} \\
\hline & & This Paper ${ }^{\mathrm{c}}$ & F94 ${ }^{\mathrm{d}}$ & This Paper ${ }^{\mathrm{c}}$ & $\mathrm{W}_{0} 3^{\mathrm{d}}$ \\
\hline $\mathrm{SiC}_{2}$ & 57.6 & $1.53(14)$ & $\ldots$ & $2.4(-6)$ & $3.1(-6)$ \\
\hline${ }^{29} \mathrm{SiC}_{2}$ & $\ldots$ & $2.26(13)$ & $\cdots$ & $3.6(-7)$ & $\ldots$ \\
\hline $\mathrm{SiS}$ & 29.6 & $2.96(14)$ & $\ldots$ & $3.4(-6)$ & $3.1(-6)$ \\
\hline $\mathrm{C}_{4} \mathrm{H}$ & 53.9 & $3.04(14)$ & $<5.54(13)$ & $4.0(-6)$ & $<1.7(-6)$ \\
\hline $\mathrm{HC}_{3} \mathrm{~N}$ & 41.0 & $7.69(13)$ & $2.7 \pm 2.3(14)$ & $1.3(-6)$ & $2.4(-6)$ \\
\hline $\mathrm{CO}$ & $\ldots$ & $1.63(17)$ & $\ldots$ & $\ldots$ & $\ldots$ \\
\hline${ }^{13} \mathrm{CO}$ & $\ldots$ & $1.35(16)$ & $\ldots$ & $\ldots$ & $\ldots$ \\
\hline $\mathrm{C}^{17} \mathrm{O}$ & $\ldots$ & $6.89(14)$ & $\ldots$ & $\ldots$ & $\ldots$ \\
\hline $\mathrm{CS}$ & $\cdots$ & $1.72(14)$ & $\cdots$ & $2.0(-6)$ & $2.5(-6)$ \\
\hline${ }^{13} \mathrm{CS}$ & $\ldots$ & $1.28(13)$ & $\ldots$ & $1.5(-7)$ & $\ldots$ \\
\hline $\mathrm{C}^{33} \mathrm{~S}$ & $\ldots$ & $6.18(12)$ & $\ldots$ & $7.2(-8)$ & $\ldots$ \\
\hline$C^{34} S$ & $\ldots$ & $2.58(13)$ & $\ldots$ & $3.0(-7)$ & $\ldots$ \\
\hline $\mathrm{SiO}$ & $\ldots$ & $2.15(13)$ & $\ldots$ & $7.0(-7)$ & $1.0(-6)$ \\
\hline${ }^{30} \mathrm{SiO}$ & $\ldots$ & $2.45(12)$ & $\ldots$ & $8.0(-8)$ & $\ldots$ \\
\hline${ }^{29} \mathrm{SiO}$ & $\ldots$ & $2.43(12)$ & $\ldots$ & $7.9(-8)$ & $\ldots$ \\
\hline $\mathrm{HCN}$ & $\ldots$ & $1.10(14)$ & $5.13 \mathrm{e} 15$ & $1.2(-6)$ & $1.1(-5)$ \\
\hline $\mathrm{H}^{13} \mathrm{CN}$ & $\ldots$ & $1.83(13)$ & $\ldots$ & $2.0(-7)$ & $3.0(-7)$ \\
\hline $\mathrm{CN}$ & $\ldots$ & $1.22(15)$ & $\ldots$ & $2.6(-5)$ & $2.0(-5)$ \\
\hline $\mathrm{C}_{2} \mathrm{H}$ & $\ldots$ & $7.43(14)$ & $4.0 \pm 2.0(14)$ & $5.4(-6)$ & $6.9(-6)$ \\
\hline $\mathrm{C}_{3} \mathrm{~N}$ & $\cdots$ & $2.16(13)$ & $\ldots$ & $1.9(-6)$ & $2.6(-6)$ \\
\hline $\mathrm{CH}_{3} \mathrm{CN}$ & $\cdots$ & $7.88(12)$ & $\cdots$ & $1.1(-7)$ & $<1.3(-7)$ \\
\hline
\end{tabular}

Notes.

a $x(y)$ represents $x \times 10^{y}$.

b A constant excitation temperature of $40 \mathrm{~K}$ was assumed for the species for which the rotation diagrams cannot be obtained.

${ }^{c}$ For the species with optically thick emission (e.g., $\mathrm{CO}$ and $\mathrm{HCN}$ ); this gives the lower limits.

${ }^{d}$ F94: from Fukasaku et al. (1994); W03: from Woods et al. (2003).

the presence of icy comets surrounding the stars (Agúndez \& Cernicharo 2006) and/or nonequilibrium chemical processes (Cherchneff 2006). $\mathrm{HCO}^{+}$has a relatively low abundance in IRC+10216 (Glassgold 1996), and is presumably below the current detection limit even if it might be present in CIT 6 .

\subsubsection{Carbon-Bearing Molecules}

We observed abundant carbon chains and radicals in CIT 6, including $\mathrm{CO}, \mathrm{SiC}_{2}, \mathrm{CN}, \mathrm{HCN}, \mathrm{CS}, \mathrm{C}_{2} \mathrm{H}, \mathrm{C}_{3} \mathrm{~N}, \mathrm{C}_{4} \mathrm{H}, \mathrm{HC}_{3} \mathrm{~N}$, and $\mathrm{CH}_{3} \mathrm{CN}$, all of which are linear. This characteristic feature is similar to those of IRC+10216 and TMC 1 (see Cernicharo et al. 2000), although these lines are much fainter in CIT 6.

The most intriguing characteristic of CIT 6 is the strong CN emission. The integrated intensity ratio of the $\mathrm{CN}(2-1)$ group and the ${ }^{13} \mathrm{CO}(2-1)$ transition is 4.6, a factor of 2.2 larger than the value in IRC+10216 (He et al. 2008). CN is mainly formed through the photodissociation of $\mathrm{HCN}$,

$$
\mathrm{HCN}+h v \rightarrow \mathrm{CN}+\mathrm{H}
$$

According to $\mathrm{He}$ et al. (2008), the $\mathrm{H}^{13} \mathrm{CN}(3-2) /{ }^{13} \mathrm{CO}(2-1)$ integrated intensity ratio in IRC+10216 is 4.5 , a factor of 3.2 larger than that in CIT 6. Therefore, our observations provide strong evidence that reaction (3) dominates the chemistry of $\mathrm{CN}$ and $\mathrm{HCN}$ in AGB stars and the photodissociation is more efficient in the more evolved C-rich envelope CIT 6.

The above discussion also suggests that about $30 \%$ of the $\mathrm{CN}$ formed from $\mathrm{HCN}$ has been destroyed. On the other hand, CN can be reprocessed into $\mathrm{HC}_{3} \mathrm{~N}$ through the reaction

$$
\mathrm{CN}+\mathrm{C}_{2} \mathrm{H}_{2} \rightarrow \mathrm{HC}_{3} \mathrm{~N}+\mathrm{H} \text {. }
$$

We do find that the $\mathrm{HC}_{3} \mathrm{~N}$ line intensities relative to the ${ }^{13} \mathrm{CO}$ (2-1) transition in CIT 6 are a factor of $\sim 3$ larger than those in IRC+10216, indicating efficient formation of $\mathrm{HC}_{3} \mathrm{~N}$ in CIT 6 . We did not find evidence for the enhancement of the $\mathrm{C}_{3} \mathrm{~N}$ radical, suggesting that photodissociation of $\mathrm{HC}_{3} \mathrm{~N}$ into $\mathrm{C}_{3} \mathrm{~N}$ is insignificant in this object.

CIT 6 shows strong $\mathrm{C}_{2} \mathrm{H}$ emission. The $\mathrm{C}_{2} \mathrm{H}$ radical is dominantly produced through the photodissociation reaction

$$
\mathrm{C}_{2} \mathrm{H}_{2}+h v \rightarrow \mathrm{C}_{2} \mathrm{H}+\mathrm{H} \text {. }
$$

Our observations show that the $\mathrm{C}_{2} \mathrm{H}$ line intensities relative to the ${ }^{13} \mathrm{CO}(2-1)$ transition in CIT 6 are almost the same at those in IRC+10216, suggesting that there is no significant $\mathrm{C}_{2} \mathrm{H}$ enhancement in CIT 6 compared with IRC+10216. This probably has an implication that $\mathrm{C}_{2} \mathrm{H}$ is dominantly processed in early AGB stages. Since $\mathrm{C}_{2} \mathrm{H}$ and $\mathrm{HC}_{3} \mathrm{~N}$ have the same chemical precursor, the $f\left(\mathrm{C}_{2} \mathrm{H}\right) / f\left(\mathrm{HC}_{3} \mathrm{~N}\right)$ abundance ratio can be used to test the chemical formation path (Wootten et al. 1980). Our results yield a ratio of 4.2 for $f\left(\mathrm{C}_{2} \mathrm{H}\right) / f\left(\mathrm{HC}_{3} \mathrm{~N}\right)$, which is in good agreement with those found in interstellar clouds by Wootten et al. (1980) and is consistent with the prediction of gas phase chemistry.

On the other hand, as shown in Figures 3 and $4, \mathrm{HC}_{3} \mathrm{~N}$ lines show profiles that differ from those of the $\mathrm{C}_{2} \mathrm{H}$ lines. This suggests that the $f\left(\mathrm{C}_{2} \mathrm{H}\right) / f\left(\mathrm{HC}_{3} \mathrm{~N}\right)$ ratio is not a constant in the envelope. The chemical structures in the red and blue sides of the star are not identical. This is probably a consequence of an inhomogeneous density distribution or physical environment. A complete understanding of the molecular environment of CIT 6 calls for a comprehensive 3D photochemistry model and highresolution mapping observations.

$\mathrm{C}_{4} \mathrm{H}$ is positively detected in CIT 6. The $\mathrm{C}_{4} \mathrm{H}$ radical can be formed via

$$
\mathrm{C}_{2} \mathrm{H}_{2}+\mathrm{C}_{2} \rightarrow \mathrm{C}_{4} \mathrm{H}+\mathrm{H} \text {. }
$$

Nejad \& Millar (1987) suggested that ion-molecule reactions also play an important role for the production of $\mathrm{C}_{4} \mathrm{H}$, unlike those for $\mathrm{HC}_{3} \mathrm{~N}$. Based on millimeter interferometer observation, Dayal \& Bieging (1993) found that the photochemical model underestimates the $\mathrm{C}_{4} \mathrm{H}$ abundance in IRC+10216 by a factor of 5. Our observations suggest that CIT 6 has a $f\left(\mathrm{C}_{4} \mathrm{H}\right)$ / $f\left(\mathrm{HC}_{3} \mathrm{~N}\right)$ abundance ratio of 3.1, which is lower than that in IRC +10216 (He et al. 2008) by a factor of $\sim 3$. On the other hand, $\mathrm{C}_{4} \mathrm{H}$ can be photodissociated into $\mathrm{C}_{2} \mathrm{H}$. However, as no enhancement of $\mathrm{C}_{2} \mathrm{H}$ is found in CIT 6, destruction of $\mathrm{C}_{4} \mathrm{H}$ should be insignificant in this $\mathrm{C}$-rich envelope. Therefore, the high radical abundance of $\mathrm{C}_{4} \mathrm{H}$ in IRC +10216 still remains mystery.

$\mathrm{CH}_{3} \mathrm{CN}$ is a new finding for this $\mathrm{C}$-rich envelope. This molecule is a symmetric top and has been widely used as diagnostics of excitation temperature. We detected only one weak $\mathrm{CH}_{3} \mathrm{CN}$ line in CIT 6, and thus cannot use it to derive an excitation temperature. $\mathrm{CH}_{3} \mathrm{CN}$ can be produced via

$$
\mathrm{CH}_{3}^{+}+\mathrm{HCN} \rightarrow \mathrm{CH}_{3} \mathrm{CNH}^{+},
$$

followed by

$$
\mathrm{CH}_{3} \mathrm{CNH}^{+}+\mathrm{e} \rightarrow \mathrm{CH}_{3} \mathrm{CN}+\mathrm{H} \text {. }
$$

The formation of $\mathrm{CH}_{3} \mathrm{CN}$ may be very efficient in CIT 6 since strong $\mathrm{HCN}$ emission is detected. CIT 6 has a $\mathrm{CH}_{3} \mathrm{CN}$ $(12-11) /{ }^{13} \mathrm{CO}(2-1)$ integrated intensity ratio of 0.058 , in 
good agreement with the value of 0.043 in IRC+10216 (He et al. 2008).

Strong CS emission has been detected in our survey. According to Willacy \& Cherchneff (1998), CS can be rapidly destroyed by shocks which might occur after a star leaves the AGB stage and ejects material in a very fast wind (Herpin et al. 2002). Therefore, the high abundance of CS in CIT 6 suggests that shocks are not important for the chemistry in this C-rich envelope.

\subsubsection{Silicon-Bearing Molecules}

Three refractory $\mathrm{Si}$-bearing species $\left(\mathrm{SiO}, \mathrm{SiS}\right.$, and $\left.\mathrm{SiC}_{2}\right)$ were detected in CIT 6. Although other Si-bearing species were detected in IRC+10216 (Cernicharo et al. 2000), emission from the other Si-bearing species is relatively faint and should be below the detection limit of our observations of CIT 6 .

We find that the abundances of $\mathrm{SiO}$ and $\mathrm{SiC}_{2}$ in CIT 6 are similar to those in IRC+10216 determined by He et al. (2008). Although the situation may be complicated by optical depth effects, the $\mathrm{HCN} / \mathrm{SiO}$ line-intensity ratio has the potential to provide a useful tool to discriminate between $\mathrm{C}$-rich and $\mathrm{O}$-rich envelopes and is a good tracer of the mass-loss rate for $\mathrm{M}$ and $\mathrm{S}$ stars (see e.g., Bieging et al. 2000). The HCN (3-2)/SiO (6-5) intensity ratio in CIT 6 is 8.4 , in good agreement the value of 9.7 in IRC+10216 (He et al. 2008). There is no evidence showing that the $\mathrm{HCN} / \mathrm{SiO}$ line-intensity ratio has dependence on the mass loss rate of C-rich stars. González Delgado et al. (2003) and Schöier et al. (2006) found a correlation between the massloss rate and the $\mathrm{SiO}$ abundance for AGB stars. This is described as freeze-out of $\mathrm{SiO}$ molecules onto dust grains. The similarity of the $\mathrm{SiO}$ abundances in CIT 6 and IRC+10216 suggests that the depletion of $\mathrm{SiO}$ onto dust grains might be insignificant for the two C-rich envelopes.

Our observations show that the SiS abundance in CIT 6 is lower than that in IRC+10216. The SiS (14-13)/SiO (6-5) intensity ratio in CIT 6 is 1.1 , about half of that in IRC+10216 found by $\mathrm{He}$ et al. (2008). Schöier et al. (2007) did not find a strong correlation between the mass loss rate and the $\mathrm{SiS}$ abundance, suggesting that $\mathrm{SiS}$ molecules are less likely to be depleted onto dust grains than $\mathrm{SiO}$ molecules. Therefore, freeze-out should not be the reason for the depletion of $\mathrm{SiS}$ in CIT 6 since no depletion of $\mathrm{SiO}$ is found for this object. On the other hand, with a high efficiency, SiS can be photodissociated into $\mathrm{Si}^{+}$, which initiates circumstellar $\mathrm{SiC}_{n}$ chemistry (MacKay \& Charnley 1999). Hence, we infer that efficient photodissociation in CIT 6 has destroyed $\mathrm{SiS}$, and silicon chemistry has been ongoing in this evolved $\mathrm{C}$-star envelope. Interferometric observations of these $\mathrm{Si}$ bearing molecules are obviously needed to verify the conjecture.

\subsection{Isotopic Ratios}

Isotopic ratios of various elements provide substantial tests for nucleosynthesis of low and intermediate mass stars (LIMS). When a LIMS evolves into the AGB stage, the nucleosynthesized products synthesized through the $\mathrm{CNO}$ cycle inside the star are dredged up to the surface and are then ejected into the circumstellar envelope. Consequently, the isotopic composition in the circumstellar shell can be markedly changed. Based on the fractional abundances proposed in Table 3, we deduce the isotopic ratios (or their lower limits) of carbon, oxygen, silicon, and sulfur in CIT 6. The results are listed in Table 4. The errors estimated from the measurement and calibration are given.
Table 4

Isotopic Abundance Ratios

\begin{tabular}{|c|c|c|c|c|}
\hline \multirow[t]{2}{*}{ Isotopic Ratio } & \multicolumn{2}{|c|}{ CIT 6} & \multirow[t]{2}{*}{$\mathrm{IRC}+10216^{\mathrm{a}}$} & \multirow[t]{2}{*}{ Solar $^{\mathrm{b}}$} \\
\hline & Sepcies & Value $^{\mathrm{c}}$ & & \\
\hline \multirow[t]{4}{*}{${ }^{12} \mathrm{C} /{ }^{13} \mathrm{C}$} & ${ }^{12} C^{34} S /{ }^{13} C^{32} S$ & $45.4 \pm 4.9^{\mathrm{d}}$ & $45 \pm 3$ & 89 \\
\hline & ${ }^{12} \mathrm{CO} /{ }^{13} \mathrm{CO}$ & $12.1 \pm 1.3^{\mathrm{e}}$ & $\ldots$ & $\ldots$ \\
\hline & ${ }^{12} \mathrm{CS} /{ }^{13} \mathrm{CS}$ & $13.4 \pm 1.7^{\mathrm{e}}$ & $\ldots$ & $\ldots$ \\
\hline & $\mathrm{H}^{12} \mathrm{CN} / \mathrm{H}^{13} \mathrm{CN}$ & $6.0 \pm 0.7^{\mathrm{e}}$ & $\ldots$ & $\ldots$ \\
\hline \multirow[t]{2}{*}{${ }^{16} \mathrm{O} /{ }^{17} \mathrm{O}$} & ${ }^{13} \mathrm{C}^{16} \mathrm{O} /{ }^{12} \mathrm{C}^{17} \mathrm{O}$ & $890 \pm 97^{\mathrm{f}}$ & $\ldots$ & 2680 \\
\hline & $\mathrm{C}^{16} \mathrm{O} / \mathrm{C}^{17} \mathrm{O}$ & $237 \pm 26^{\mathrm{e}}$ & $\ldots$ & $\ldots$ \\
\hline${ }^{29} \mathrm{Si} /{ }^{30} \mathrm{Si}$ & ${ }^{29} \mathrm{SiO} /{ }^{30} \mathrm{SiO}$ & $1.0 \pm 0.4$ & $1.45 \pm 0.13$ & 1.52 \\
\hline${ }^{28} \mathrm{Si} /{ }^{30} \mathrm{Si}$ & ${ }^{28} \mathrm{SiO} /{ }^{30} \mathrm{SiO}$ & $8.8 \pm 1.9^{\mathrm{e}}$ & $20.3 \pm 2.0^{\mathrm{e}}$ & 29.9 \\
\hline \multirow[t]{2}{*}{${ }^{28} \mathrm{Si} /{ }^{29} \mathrm{Si}$} & ${ }^{28} \mathrm{SiO} /{ }^{29} \mathrm{SiO}$ & $8.9 \pm 2.8^{\mathrm{e}}$ & $15.4 \pm 2.0^{\mathrm{e}}$ & 19.6 \\
\hline & ${ }^{28} \mathrm{SiC}_{2}{ }^{29} \mathrm{SiC}_{2}$ & $6.7 \pm 3.1^{\mathrm{e}}$ & $\ldots$ & $\ldots$ \\
\hline${ }^{32} \mathrm{~S} /{ }^{34} \mathrm{~S}$ & $\mathrm{C}^{32} \mathrm{~S} / \mathrm{C}^{34} \mathrm{~S}$ & $6.7 \pm 1.2^{\mathrm{e}}$ & $21.8 \pm 2.6$ & 22.5 \\
\hline${ }^{33} \mathrm{~S} /{ }^{34} \mathrm{~S}$ & $\mathrm{C}^{33} \mathrm{~S} / \mathrm{C}^{34} \mathrm{~S}$ & $0.2 \pm 0.2$ & $0.18 \pm 0.1$ & 0.18 \\
\hline
\end{tabular}

Notes.

${ }^{a}$ From Cernicharo et al. (2000)

b From Lodders (2003).

c The errors are estimated based on the measurement and calibration uncertainties.

${ }^{\mathrm{d}}$ Assume that the ${ }^{34} \mathrm{~S} /{ }^{32} \mathrm{~S}$ ratio is solar.

e Should be treated as lower limits due to opacity effect.

f Adopted: ${ }^{12} \mathrm{C} /{ }^{13} \mathrm{C}=45.4$.

For comparison, we also list the isotopic ratios for IRC+10216 (Cernicharo et al. 2000) and the Sun (Lodders 2003).

\subsubsection{Carbon}

The ${ }^{12} \mathrm{C} /{ }^{13} \mathrm{C}$ abundance ratio is the most studied isotopic abundance in LIMS. Standard stellar models predict that the ${ }^{12} \mathrm{C} /{ }^{13} \mathrm{C}$ abundance ratio can be significantly increased during the nucleosynthesis and dredge-up processes in the AGB stage. However, extensive observations have shown that the ${ }^{12} \mathrm{C} /{ }^{13} \mathrm{C}$ abundance ratios in LIMSs are considerably lower than those expected by standard stellar models (e.g., Charbonnel \& do Nascimento 1998). Charbonnel (1995) proposed an extra mixing process to account for the low ${ }^{12} \mathrm{C} /{ }^{13} \mathrm{C}$. In low-mass AGB stars, the nonstandard mixing called "cool bottom processing" may decrease the ${ }^{12} \mathrm{C} /{ }^{13} \mathrm{C}$ ratio to $\sim 4$ (Sackmann \& Boothroyd 1999; Boothroyd \& Sackmann 1999). For AGB stars more massive than $\sim 4 M_{\odot}$, the hot bottom burning may take place and induce ${ }^{12} \mathrm{C} /{ }^{13} \mathrm{C}$ to further decrease to its equilibrium value of $\sim 3.5$ (Frost et al. 1998). Current observations of the CO isotopologues in PNs (Balser et al. 2002; Josselin \& Bachiller 2003) suggest that the ${ }^{12} \mathrm{C} /{ }^{13} \mathrm{C}$ ratio is in the range of 2.2-40, supporting the theory that includs nonstandard mixing processes.

Three ${ }^{13} \mathrm{C}$-bearing species have been detected in this survey, including ${ }^{13} \mathrm{CO},{ }^{13} \mathrm{CS}$, and $\mathrm{H}^{13} \mathrm{CN}$. However, their main lines are likely optically thick. Therefore, the abundance ratios of $\mathrm{CO}, \mathrm{CS}$, and $\mathrm{HCN}$ and their isotopologues only provide lower limits of the ${ }^{12} \mathrm{C} /{ }^{13} \mathrm{C}$ ratio. Our results are in good agreement with those presented by Sopka et al. (1989), who derived the abundance ratios ${ }^{12} \mathrm{CO} /{ }^{13} \mathrm{CO} \gtrsim 25 \pm 10$ and $\mathrm{H}^{12} \mathrm{CN} /$ $\mathrm{H}^{13} \mathrm{CN} \gtrsim 5.4$ for CIT 6 .

We have detected the rare isotopes, ${ }^{12} \mathrm{C}^{34} \mathrm{~S}$ and ${ }^{13} \mathrm{C}^{32} \mathrm{~S}$. If the ${ }^{32} \mathrm{~S} /{ }^{34} \mathrm{~S}$ abundance ratio were known, we could obtain the ${ }^{12} \mathrm{C} /{ }^{13} \mathrm{C}$ ratio using the two optically thin species. Cernicharo et al. (2000) found that the sulfur isotopic ratios in IRC+10216 are close to solar. Therefore, we reasonably assume that the ${ }^{32} \mathrm{~S} /{ }^{34} \mathrm{~S}$ ratio in CIT 6 is the solar value. It follows that we obtained the ${ }^{12} \mathrm{C} /{ }^{13} \mathrm{C}$ ratio of $45.4 \pm 4.9$ in CIT 6 , which is in perfect agreement with that found in IRC+10216 and is 
significantly lower than the solar value. The ${ }^{12} \mathrm{C} /{ }^{13} \mathrm{C}$ ratios found in these $\mathrm{C}$-rich envelopes are also lower than the value of $75 \pm 9$ in the Orion Bar proposed by Keene et al. (1998) using the $\mathrm{C}^{18} \mathrm{O} /{ }^{13} \mathrm{C}^{18} \mathrm{O}$ abundance ratio. This is consistent with the hypothesis that nonstandard mixing processes have decreased the ${ }^{12} \mathrm{C} /{ }^{13} \mathrm{C}$ ratios in the envelopes around AGB stars.

As shown in Table 4 , different ${ }^{12} \mathrm{C} /{ }^{13} \mathrm{C}$ values are obtained for CIT 6 if different species are used for the calculations. If completely ascribing the ${ }^{12} \mathrm{C} /{ }^{13} \mathrm{C}$ discrepancies found for CIT 6 to the opacity effects of the main lines, we can estimate the optical depths of the CO (2-1), CS (3-2), and HCN (3-2) lines, which are 1.3, 1.2, and 2.0, respectively. If the isotopic lines are also optically thick, the optical depths obtained here should be considered as lower limits.

\subsubsection{Oxygen}

The nucleosynthesis and dredge-up processes in the AGB stage can lead to strong enrichment of ${ }^{17} \mathrm{O}$ relative to ${ }^{16} \mathrm{O}$ and ${ }^{18} \mathrm{O}$ (see Busso 2006, for a recent review). Wannier \& Sahai (1987) found that the ${ }^{17} \mathrm{O} /{ }^{18} \mathrm{O}$ ratios in C-rich envelopes are markedly higher than the terrestrial and interstellar values, but the ${ }^{16} \mathrm{O} /{ }^{18} \mathrm{O}$ ratios are comparable to the solar value.

We have detected $\mathrm{C}^{17} \mathrm{O}$, allowing us to derive the ${ }^{16} \mathrm{O} /{ }^{17} \mathrm{O}$ ratio in CIT 6. The $\mathrm{C}^{16} \mathrm{O} / \mathrm{C}^{17} \mathrm{O}$ abundance ratio gives a lower limit of $237 \pm 26$. We may also use the optically thin species ${ }^{13} \mathrm{C}^{16} \mathrm{O}$ and ${ }^{12} \mathrm{C}^{17} \mathrm{O}$ to derive the ${ }^{16} \mathrm{O} /{ }^{17} \mathrm{O}$ ratio. Assuming ${ }^{12} \mathrm{C} /{ }^{13} \mathrm{C}=45.4$ (see above), we obtain a ${ }^{16} \mathrm{O} /{ }^{17} \mathrm{O}$ ratio of $890 \pm 97$. Cernicharo et al. (2000) did not obtain the oxygen isotopic ratios. Kahane et al. (1992) calculated the ${ }^{16} \mathrm{O} /{ }^{17} \mathrm{O}$ ratio for a sample of $\mathrm{C}$-rich envelopes. They found that ${ }^{16} \mathrm{O} /{ }^{17} \mathrm{O}=$ $840_{-270}^{+450}$ and $840_{-170}^{+230}$ for CIT 6 and IRC +10216 , respectively. These values are in good agreement with our result, agree with each other, and are lower than the solar value by a factor of about 3, which is consistent with predictions of stellar models.

No ${ }^{18} \mathrm{O}$-bearing species was detected. The nondetection of the $\mathrm{C}^{18} \mathrm{O}(2-1)$ transition at $219560 \mathrm{MHz}$ seems to suggest that ${ }^{17} \mathrm{O} /{ }^{18} \mathrm{O}>1$ in CIT 6 . However, this result should be taken with some caution since the $\mathrm{C}^{18} \mathrm{O}$ line is very close to the edge of the spectrum.

\subsubsection{Silicon and Sulfur}

The nucleosynthesis in LIMS is expected to hardly affect the elements in the 3rd row of the periodic table, such as Si and S. Cernicharo et al. (2000) indeed found that the Si and S isotopic ratios in IRC+10216 are compatible with the solar values.

The silicon isotopes, ${ }^{29} \mathrm{Si}$ and ${ }^{30} \mathrm{Si}$, have been detected through faint emission from ${ }^{29} \mathrm{SiO},{ }^{30} \mathrm{SiO}$, and ${ }^{29} \mathrm{SiC}_{2}$. Since the $\mathrm{SiO}$ and $\mathrm{SiC}_{2}$ lines are probably optically thick, the lower limits of the ${ }^{28} \mathrm{Si} /{ }^{30} \mathrm{Si}$ and ${ }^{28} \mathrm{Si} /{ }^{29} \mathrm{Si}$ ratios were derived. Given the low abundances of ${ }^{29} \mathrm{Si}$ and ${ }^{30} \mathrm{Si}$, the ${ }^{29} \mathrm{Si} /{ }^{30} \mathrm{Si}$ ratio is not affected by opacity effects. We obtained ${ }^{29} \mathrm{Si} /{ }^{30} \mathrm{Si}=1.0 \pm 0.4$, comparable with the values in IRC+10216 and those in the Sun.

The $C^{32} S / C^{34} S$ ratio gives a lower limit of ${ }^{32} S /{ }^{34} S$ in CIT 6. $\mathrm{C}^{33} \mathrm{~S}$ was only marginally detected. The two optically thin species, $\mathrm{C}^{33} \mathrm{~S}$ and $\mathrm{C}^{34} \mathrm{~S}$, give a ${ }^{33} \mathrm{~S} /{ }^{34} \mathrm{~S}$ ratio of $0.2 \pm 0.2$. Consequently, we did not find a significant deviation of the $\mathrm{S}$ isotopic ratios in CIT 6 from those in IRC+10216 and in the Sun.

\subsection{Is IRC+10216 Unique?}

Given its brightness and abundant molecular emission, IRC +10216 is the most surveyed object and has frequently served as a standard reference for studying circumstellar chemistry. A commonly asked question is whether IRC+10216 can truly represent $\mathrm{C}$-rich $\mathrm{AGB}$ stars. To investigate the problem, we systematically compare the spectra of CIT 6 with those of IRC +10216 obtained in the same survey program $(\mathrm{He}$ et al. 2008).

We find that all lines detected in this work have also been observed in IRC+10216, and all the strong lines detected in IRC+10216 are seen in CIT 6. In Figure 6, we compare the intensity ratios of the lines detected in both objects. The results show that the line-intensity ratios in the two objects are in agreement, within one order of magnitude, with an average value of 0.08 with a standard deviation of 0.05 . The intensity ratios, however, might be affected by beam dilution. CIT 6 is a more compact object and thus suffers from a larger beam dilution effect. If we correct for the beam dilution effect, the I(CIT 6) $/ I($ IRC+10216) ratios should increase by a factor of $\xi$, where

$$
\xi=\left(1+\frac{\theta_{b}^{2}}{\theta_{\text {CIT } 6}^{2}}\right) /\left(1+\frac{\theta_{b}^{2}}{\theta_{\text {IRC }+10216}^{2}}\right)
$$

Assuming $\theta_{\mathrm{CIT} 6}=20^{\prime \prime}$ and $\theta_{\mathrm{IRC}+10216}=30^{\prime \prime}$ (Fukasaku et al. 1994) and using $\theta_{b}=40^{\prime \prime}$ and $30^{\prime \prime}$ for the ARO $12 \mathrm{~m}$ and the SMT, respectively, we obtain the $\xi$ values of 1.8 and 1.6 for the $12 \mathrm{~m}$ and SMT data, respectively. While recognizing that Equation (9) assumes the distribution of brightness temperature to be Gaussian which is probably not realistic, the result does suggest that there is no large correction factor difference between the $2 \mathrm{~mm}$ and $3 \mathrm{~mm}$ bands. Our conclusion that for most of the species the $I($ CIT 6$) / I(I R C+10216)$ line ratios are in good agreement therefore stands. Consequently, we conclude that IRC +10216 is indeed a likely representative of C-rich envelopes, although comparisons with a larger sample of objects will be needed to make a stronger statement. The richness of molecular lines in the spectra of IRC+10216 is mainly due to its relatively nearby distance and not due to any special circumstances.

Figure 6 also shows that there are a few molecular species for which the $I($ CIT 6) $/ I($ IRC+10216) ratios depart from the average value. For the $\mathrm{CN}$ and $\mathrm{HC}_{3} \mathrm{~N}$ lines, the ratios are higher, whereas for $\mathrm{HCN}, \mathrm{SiS}$, and $\mathrm{C}_{4} \mathrm{H}$, the ratios are lower. As discussed in Section 4.1.2, this partly reflects the chemical evolution in the circumstellar envelope around the more-evolved AGB star CIT 6. However, the cause of the abnormally strong $\mathrm{C}_{4} \mathrm{H}$ emission in IRC+10216 remains unknown.

Far-IR (FIR) spectra of CIT 6 and IRC+10216 have been obtained by the Infrared Space Observatory (ISO) Long Wavelength Spectrometer (LWS) (Schöier et al. 2002; Cernicharo et al. 1996). The rotational transitions revealed by the ISO spectra can trace the inner regions of the circumstellar envelopes (Herpin et al. 2002). In Figure 7, we compare the FIR spectra of the two objects. The spectra were retrieved from the ISO archive. Inspection of the figure shows that their FIR spectra are dominated by thermal continuum emission from the dust with some superimposed molecular lines. Lindqvist et al. (2000) fitted the dust continuum of IRC +10216 with a single blackbody of $510 \mathrm{~K}$ and the continuum of CIT 6 with two blackbodies of $1000 \mathrm{~K}$ and $510 \mathrm{~K}$. In the long wavelength region, the dust temperatures of the two objects are therefore almost identical.

Figure 8 gives the continuum-subtracted ISO LWS spectra of the two C-rich envelopes. A number of lines from $\mathrm{CO}, \mathrm{HCN}$, $\mathrm{H}^{13} \mathrm{CN}$, and vibrationally excited $\mathrm{HCN}$ have been identified by Cernicharo et al. (1996) in the spectrum of IRC+10216. Figure 8 shows that the relative flux ratios of the lines detected in the two 


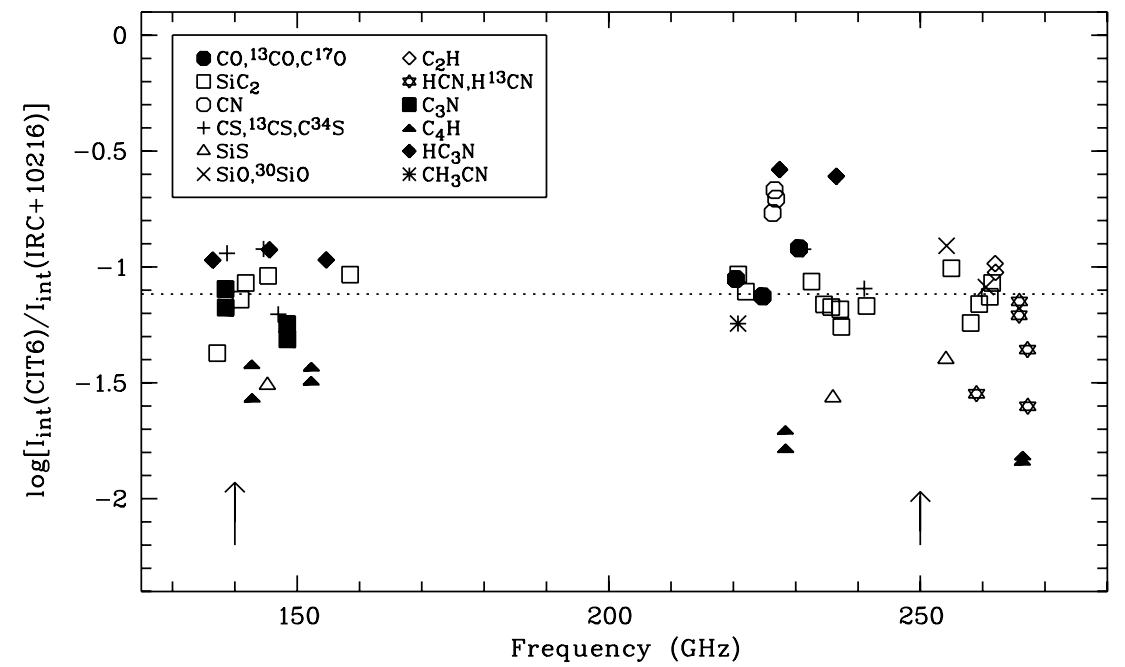

Figure 6. Integrated intensity ratios of the lines detected in CIT 6 and those detected in IRC+10216. The dotted line represents the average value. A correction of beam dilution effect will cause the ratios to increase by a factor of $\xi$. The $\log \xi$ values for the $12 \mathrm{~m}$ and SMT data are denoted by the lengths of the arrows in the lower-left and right-hand corners, respectively.

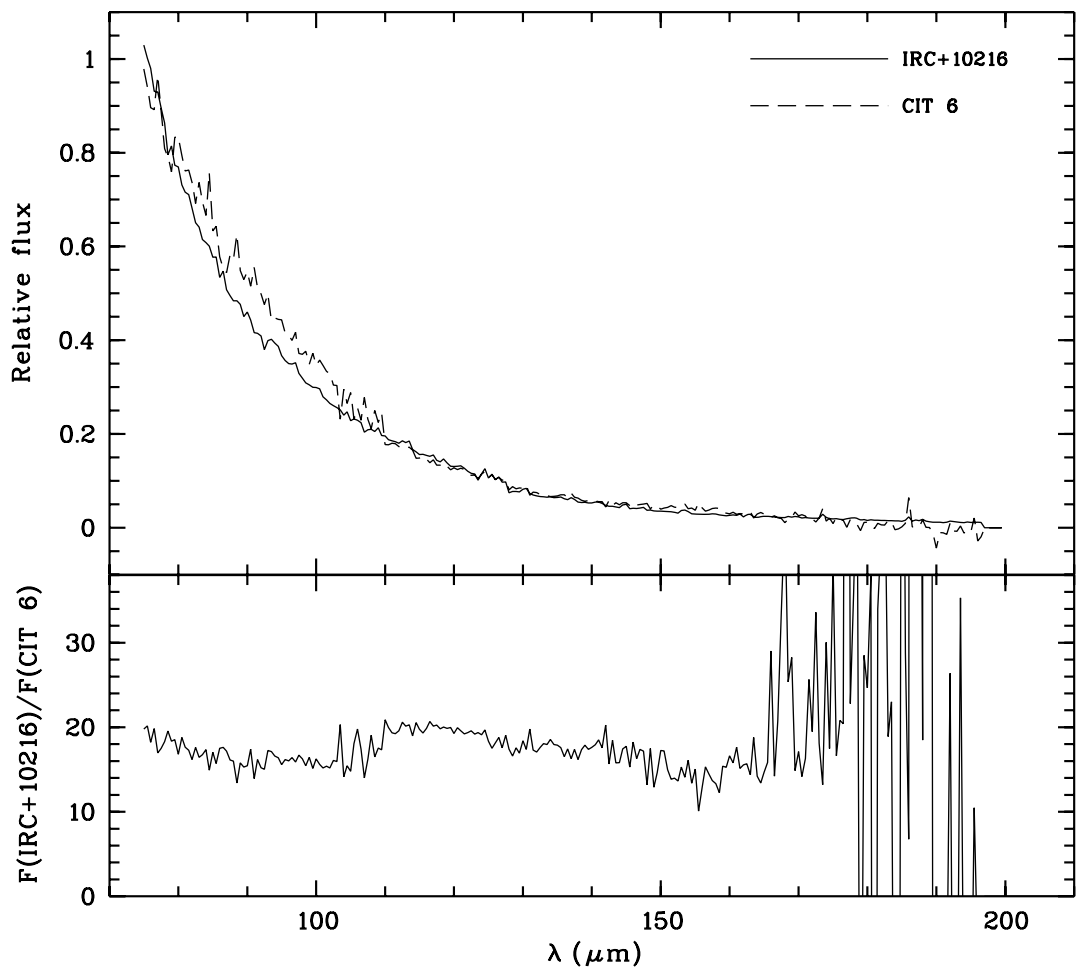

Figure 7. Upper panel: the ISO LWS spectra of IRC+10216 and CIT 6, for which the fluxes were normalized such that $F_{76 \mu \mathrm{m}}=1$; lower panel: the absolute-flux ratio of the two spectra. Note that the ratio at $\lambda>160 \mu \mathrm{m}$ bears large errors.

objects are in good agreement, although the detection of some weak lines is difficult in CIT 6 as it is fainter. The FIR line fluxes detected in IRC+10216 are a factor of about 10 higher than those in CIT 6, consistent with that found for the molecular lines at millimeter wavelengths. However, we find that the FIR dust continuum emission in IRC+10216 is a factor of about 20 times higher than that of CIT 6, as shown in Figure 7. This probably suggests that IRC +10216 has a larger dust-to-molecular gas ratio.

\subsection{Abundance Variations Expected in Later Evolutionary Stages}

Since CIT 6 has been proposed to be a highly evolved AGB star on the verge of becoming a Proto-PN (or PPN) (Schmidt et al. 2002), it would be useful to compare the molecular abundances of CIT 6 with the corresponding molecular abundances in the evolved AGB star IRC+10216 and a PPN. The archetypical PPN CRL 618 has abundant molecular emission. It is one of the brightest molecular sources in the sky and is an ideal target for investigating circumstellar chemistry (see e.g., Pardo et al. 2007). All three objects are carbon rich, and are commonly assumed to belong to a common evolutionary sequence. Any systematic difference in molecular abundances in these three objects can be used to infer properties of the processes of chemical synthesis and destruction.

Figure 9 gives the fractional abundances of the species in the three objects as a function of their photodissociation rates taken from the UMIST database for a temperature of $300 \mathrm{~K}$. 


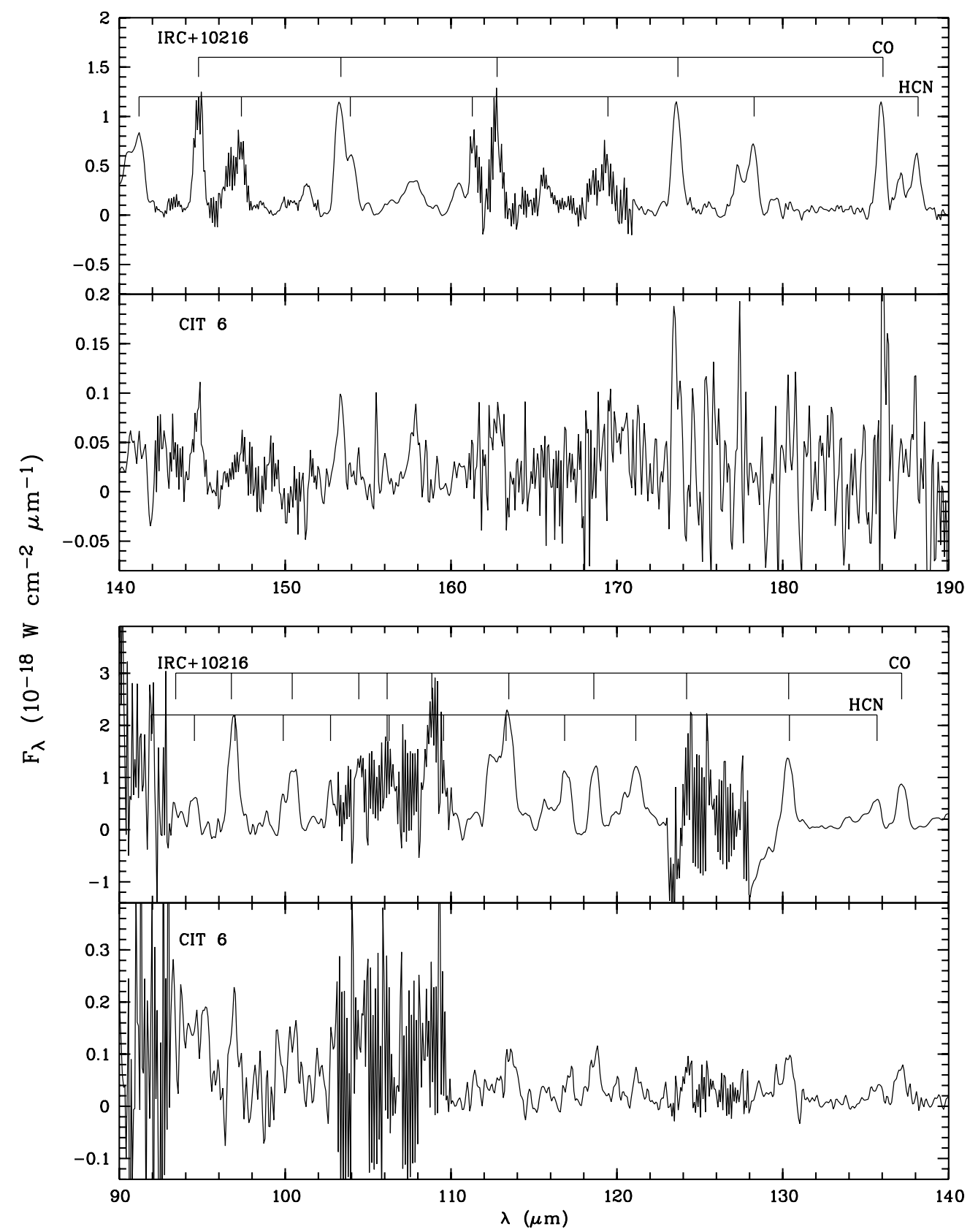

Figure 8. The continuum-subtracted ISO LWS spectra of IRC+10216 and CIT 6. The solid lines mark the CO and HCN emission identified by Cernicharo et al. (1996) in the spectrum of IRC+10216.

The abundances in IRC+10216 and CRL 618 are taken from Woods et al. (2003) and Pardo et al. (2007), respectively. To facilitate the comparison, we follow Pardo et al. (2007) and give the molecular abundances relative to $\mathrm{HC}_{3} \mathrm{~N}$. According to this figure, except for $\mathrm{CN}$ and $\mathrm{HCN}$, the molecular abundances in CIT 6 are obviously closer to those in IRC+10216 than to CRL 618. CRL 618 has lower abundances of $\mathrm{SiO}$ and CS, suggesting that destruction by shocks and depletion onto dust grains may play an important role for the chemistry in this object. Compared to the other two objects, CRL 618, having a B0 central star, is exposed in a stronger UV radiation field. However, we do not find a correlation between the abundance differences of these objects and the molecular photodissociation rates, suggesting that there are factors other than the destruction by photodissociation affecting the chemistry in these objects during the AGB-PPN transition. We do find that some molecules have been efficiently reprocessed during this transition. Sinc e the dynamical timescale of PPN is $\sim 10^{3}$ years, our results therefore suggest a rapid change of the chemical compositions after the star evolves into the PPN stage.

We should note that this study is limited to simple molecules in the gas phase. There is strong evidence from IR spectroscopy that the solid-state phase chemistry is very active in the AGB-PPN evolutionary transition, with many aromatic and aliphatic compounds being formed in the circumstellar envelope (Kwok 2004). Even some simple gas-phase molecules (e.g., acetylene and benzene) are difficult to detect via rotational transitions in the $\mathrm{mm} / \mathrm{submm}$ region, and complex organics even more so. Consequently, the technique of rotational $\mathrm{mm} / \mathrm{submm}$ spectroscopy is unable to serve as a complete diagnostic tool for 


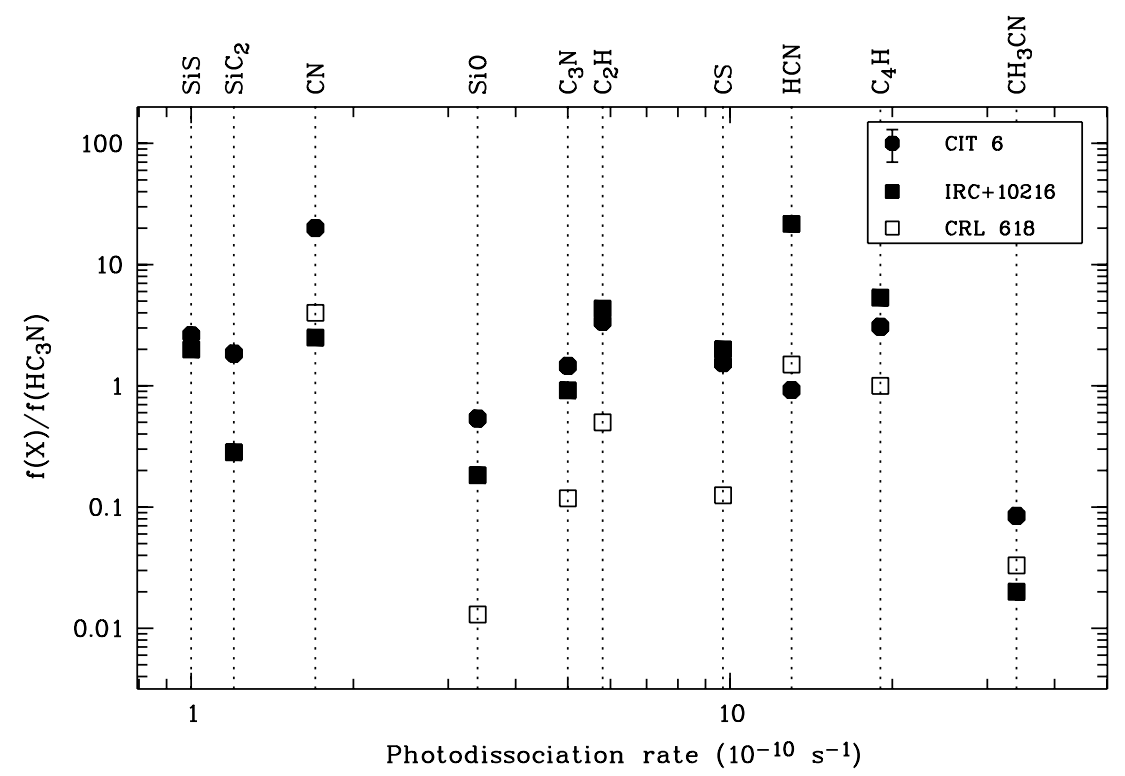

Figure 9. Abundances relative to $\mathrm{HC}_{3} \mathrm{~N}$ vs. photodissociation rates at $T=300 \mathrm{~K}$. For some species, the photodissociation rates have been shifted a littlie bit for convenience of display. The data of IRC+10216 and CRL 618 are taken from Woods et al. (2003) and Pardo et al. (2007), respectively. Typical uncertainty for the data of CIT 6 is given on the upper right. Note that the data for $\mathrm{SiS}$ and $\mathrm{SiC}_{2}$ in CRL 618 are lacking.

circumstellar chemistry. It is more useful as a probe of photo- or shock-chemistry in the PN phase, or during the formative stage of early AGB evolution.

\section{CONCLUSIONS}

The presence of rich molecular species around evolved stars provides an opportunity to study the evolution of chemistry in circumstellar envelopes, which have been widely suggested as one of the main sources of organic compounds in space. As part of our project of investigating circumstellar chemistry, this paper reports a spectral-line survey of the carbon-rich envelope CIT 6, covering the frequency range between 131-160, 219-244, and $252-268 \mathrm{GHz}$ with a high sensitivity. A total of 74 lines are reported in the survey. We identify 69 lines belonging to 21 different molecular species and isotopologues, most of which are carbon-bearing species. The new species include two carbonchain molecules, $\mathrm{C}_{4} \mathrm{H}$ and $\mathrm{CH}_{3} \mathrm{CN}$, and seven $\mathrm{C}, \mathrm{O}, \mathrm{S}$, and $\mathrm{Si}$ isotopologues. Several new transitions from known species have been detected for the first time in this object. The species with the largest number of detected emission lines in our survey is $\mathrm{SiC}_{2}$, which has 19 lines. It is followed by $\mathrm{HC}_{3} \mathrm{~N}$, with seven lines.

We find that the line profiles for some molecular species have different shapes, suggesting that the chemical structure is asymmetric in the envelope. A comprehensive 3D photochemistry model is required to account for the line intensities and profiles in CIT 6.

The excitation temperatures, column densities, and abundances of the detected molecules are determined through rotation-diagram analysis. The spectra of CIT 6 are characterized by a large $\mathrm{CN} / \mathrm{HCN}$ abundance ratio. Our results suggest that there is evidence for the photodissociation of $\mathrm{HCN}$ and $\mathrm{SiS}$ and the formation of $\mathrm{CN}$ and $\mathrm{HC}_{3} \mathrm{~N}$ in the evolved AGB envelope. The strong $\mathrm{SiO}$ and $\mathrm{CS}$ emission may suggest that depletion onto dust grains and destruction by shocks are insignificant in this object. An abundance comparison with the PPN CRL 618 implies a rapid chemical evolution after a star leaves the AGB stage.
In order to investigate whether the molecular environment of IRC +10216 is intrinsically unique, we systematically compare its spectra with those of CIT 6. According to the comparison, we find that the molecular species can be classified into three groups: (1) for most of the species, the intensity ratios of individual lines in the two objects are in good agreement with each other; (2) the emission from $\mathrm{HC}_{3} \mathrm{~N}$ and $\mathrm{CN}$ may be enhanced in CIT 6; (3) the emission from $\mathrm{SiS}, \mathrm{HCN}$, and $\mathrm{C}_{4} \mathrm{H}$ may be depleted in CIT 6 . The differences of the line-intensity ratios in the two objects are probably a consequence of chemical evolution with the exception of $\mathrm{C}_{4} \mathrm{H}$, for which a high abundance in IRC+10216 cannot be explained by photochemical models. The ISO LWS spectra show that CIT 6 has a lower continuumto-line ratio than IRC+10216, suggesting that the latter might have a larger dust-to-molecular gas ratio.

Using the same telescope settings, we also obtained the spectra of the AGB stars IRC+10216 and CRL 3068, the PPN CRL 2688, and the young PN NGC 7207. A detailed study of the chemical compositions in different evolutionary stages will be published in a separate paper.

We are grateful to the ARO staff for their help during the observing run. Otto Peng and Yu-Chin Huang assisted in the observations. We also thank Jun-ichi Nakashima and Jin-Hua $\mathrm{He}$ for useful discussions. We acknowledge the anonymous referee for comments that helped strengthen the paper. The work was supported by a grant from the Research Grants Council of the Hong Kong Special Administrative Region, China (Project No. HKU 7028/07P).

\section{REFERENCES}

Agúndez, M., \& Cernicharo, J. 2006, ApJ, 650, 374

Alksnis, A. 1995, Baltic Astron., 4, 79

Bachiller, R., Fente, A., Bujarrabal, V., Colomer, F., Loup, C., Omont, A., \& de Jong, T. 1997, A\&AS, 319, 235

Balser, D. S., McMullin, J. P., \& Wilson, T. L. 2002, ApJ, 572, 326

Bieging, J. H., Shaked, S., \& Gensheimer, P. D. 2000, ApJ, 543, 897

Boothroyd, A. I., \& Sackmann, I.-J. 1999, ApJ, 510, 232 
Bujarrabal, V., Fuente, A., \& Omont, A. 1994, A\&A, 285, 247

Busso, M. M. 2006, in IAU Symp. 234, Planetary Nebulae, ed. M. J. Barlow \& R. H. Méndez (Cambridge: Cambridge Univ. Press), 91

Cernicharo, J., Guélin, M., \& Kahane, C. 2000, A\&AS, 142, 181

Cernicharo, J., et al. 1996, A\&A, 315, L201

Charbonnel, C. 1995, ApJ, 453, L41

Charbonnel, C., \& do Nascimento, J. D. 1998, A\&A, 336, 915

Cherchneff, I. 2006, A\&A, 456, 1001

Cohen, M., \& Hitchon, K. 1996, AJ, 111, 962

Dayal, A., \& Bieging, J. H. 1993, ApJ, 407, L37

Dyck, H. M., Forbes, F. F., \& Shawl, S. J. 1971, AJ, 76, 901

Frost, C. A., Cannon, R. C., Lattanzio, J. C., Wood, P. R., \& Forestini, M. 1998, A\&A, 332, L17

Fukasaku, S., et al. 1994, ApJ, 437, 410

Glassgold, A. E. 1996, ARA\&A, 34, 241

González Delgado, D., Olofsson, H., Kerschbaum, F., Schöier, Lindqvist, M., \& Groenewegen, M. A. T. 2003, A\&A, 411, 123

Groenewegen, M. A. T., Baas, F., de JONG, T., \& Loup, C. 1996, A\&A, 306, 241

Groenewegen, M. A. T., Whitelock, P. A., Smith, C. H., \& Kerschbaum, F. 1998, MNRAS, 293, 18

He, J.-H., Dinh-V-Trung, Kwok S., Müller, H. S. P., Zhang, Y., Hasegawa, T., Peng, T. C., \& Huang, Y. C. 2008, ApJS, 177, 275

Henkel, C., Matthews, H. E., Morris, M., Terebey, S., \& Fich, M. 1985, A\&A, 147,143

Herpin, F., Goicoechea, J. R., \& Cernicharo, J. 2002, ApJ, 577, 961

Josselin, E., \& Bachiller, R. 2003, A\&A, 397, 659

Kahane, C., Cernicharo, J., Gómez-González, J., \& Guélin, M. 1992, A\&AS, 256,235

Keene, J., Schilke, P., Kooi, J., Lis, D. C., Mehringer, D. M., \& Phillips, T. G. 1998, ApJ, 494, L107

Kruszewski, A. 1968, PASP, 80, 560

Kwok, S. 2004, Nature, 430, 985

Lagadec, E., Mékarnia, D., de Freitas Pacheco, J. A., \& Dougados, C. 2005, A\&A, 433, 553

Lindqvist, M., Schöier, F.L., Lucas, R., \& Olofsson, H. 2000, A\&A, 361, 1036

Lodders, K. 2003, ApJ, 591, 1220
Lucas, R., \& Guélin, M. 1999, in IAU Symp. 191, Asymptotic Giant Branch Stars, ed. T. Le Bertre, A. Lébre, \& C. Waelkens (San Francisco, CA: ASP), 305

MacKay, D. D. S., \& Charnley, S. B. 1999, MNRAS, 302, 793

Monnier, J. D., Tuthill, P. G., \& Danchi, W. C. 2000, ApJ, 545, 957

Müller, H. S. P., Schlöder, F., Stutzki, J., \& Winnewisser, G. 2005, J. Mol Struct., 742, 215

Müller, H. S. P., Thorwirth, S., Roth, D. A., \& Winnewisser, G. 2001, A\&A 370, L49

Nejad, L. A. M., \& Millar, T. J. 1987, A\&A, 183, 279

Nummelin, A., et al. 1998, ApJS, 117, 427

Olofsson, H. 1996, in IAU Symp. 178, Molecules in Astrophysics: Probes \& Processes, ed. E. van Dishoeck (Dordrecht: Kluwer), 457

Olofsson, H. 1997, Astrophys. Space Sci., 251, 31

Pardo, J. R., Cernicharo, J., Goicoechea, J. R., Gu'elin, M., \& Ramos, A. A. 2007, ApJ, 661, 250

Pickett, H. M., Poynter, R. L., Cohen, E. A., Delitsky, M. L., Pearson, J. C., \& Muller, H. S. P. 1998, J. Quant. Spectrosc. Rad. Transfer, 60, 883

Sackmann, I.-J., \& Boothroyd, A. I. 1999, ApJ, 510, 217

Schmidt, G. D., Hines, D. C., \& Swift, S. 2002, ApJ, 576, 429

Schöier, F. L., Bast, J., Olofsson, H., \& Lindqvist, M. 2007, A\&A, 473, 871

Schöier, F. L., Olofsson, H., \& Lundgren, A. A. 2006, A\&A, 247, 255

Schöier, F. L., Ryde, N., \& Olofsson, H. 2002, A\&A, 391, 577

Sopka, R. J., Olofsson, H., Johansson, L. E. B., Nguyen-Q-Rieu, \& Zuckerman, B. 1989, A\&A, 210, 78

Teyssier, D., Hernandez, R., Bujarrabal, V., Yoshida, H., \& Phillips, T. G. 2006, A\&A, 450, 167

Ulrich, B. T., Neugebauer, G., McCammono, D., Leighton, R. B., Hughes, E. E., \& Becklin, E. 1966, ApJ, 146, 288

Wannier, P. G., \& Sahai, R. 1987, ApJ, 319, 367

Willacy, K., \& Cherchneff, I. 1998, A\&A, 330, 676

Winters, J. M., Le Bertre, T., Nyman, L.-̊,, Omont, A., \& Jeong, K. S. 2002, A\&A, 388, 609

Woods, P. M., Sch”oier, F. L., Nyman, L.-Å., \& Olofsson, H. 2003, A\&A, 402, 617

Wootten, A., Bozyan, E. P., \& Garrett, D. B. 1980, ApJ, 239, 844

Ziurys, L. M., Milam, S. N., Apponi, A. J., \& Woolf, N. J. 2007, Nature, 447, 1094 